Original Research Paper

\title{
Experimental Comparison of the Known Hypotheses of the Lateral Buckling for Semi-Slender Pinned Columns
}

\author{
Krzysztof Murawski \\ Independent Researcher, Poland
}

\section{Article history}

Received: 16-02-2021

Revised: 01-04-2021

Accepted: 04-04-2021

Email: k.murawski@interia.pl

\begin{abstract}
The paper presents the comparison of experimental results obtained from tests on semi-slender columns with pinned ends made of steel R35 to simplifications and hypotheses of loss of stability by lateral buckling in elastic-plastic states of columns axially compressed by force. The Tetmajer-Jasiński's and Johnson-Ostenfeld's simplifications, as well as the hypotheses given by Engesser and Kármán and Shanley, Ylinen, Březina, Pearson and Bleich and Vol'mir and the author's one approximated, are analyzed. The graphs of surface functions of critical compressive stress $\sigma_{c r}(A$, $L^{*} t$ ) depending on a cross-section area and length times thickness product are presented as the theoretical examples of thin-walled cylindrical and square columns made of steel R35. In order to compare the experimental results with other simplifications and hypotheses are shown in the adequate ranges for elastic-plastic states as the graphs of the functions of critical compressive stress depending on slenderness ratio $\sigma_{c r}(\lambda)$.
\end{abstract}

Keywords: Stability, Buckling, Elastic-Plastic States, Semi-Slender, Column

\section{Introduction}

When is considered the application of shell elements in load-bearing structures, accordingly, the first issue to analyze is their load capacity to sustain axial loads, i.e., their stability and susceptibility to potential buckling collapse mechanisms that could compromise the structure and occupant safety. In the case of very slender columns, this refers to the problem of stability in elastic states.

The basic theory of slender rods losing stability in elastic states, as known, has been originally formulated by Euler (1744). He first introduced the concept of critical load $P_{c r}$ and presented, according to his theory, the differential equation of an elastic deflected central line.

The stability phenomenon of semi slender columns in elastic-plastic states was researched too, by (Tetmajer, 1886; Jasiński, 1894; Engesser, 1889; 1895; Ostenfeld, 1898; Kármán, 1908; 1910; Shanley, 1947; Stowell, 1948; Bijlaard, 1949; Bleich, 1952; Broszko, 1953; Ylinen, 1956; Radhakrishnan, 1956; Gerard and Becker, 1957; Gerard, 1957; 1962; Seide et al., 1960; Vol'mir, 1965; Březina, 1966).

\section{Review of the Literature}

This phenomenon was later researched by others.
Yiotis et al. (1982) presented a solution methodology for investigating the stability of rectangular box-shaped structures subjected to transverse uniformly distributed compressive loading. Nakashima et al. (1994) presented the results of a pilot test conducted for evaluating the energy dissipation behavior of shear panels made of low yield steel whose $0.2 \%$ offset yield stress is $120 \mathrm{MPa}$. Brank et al. (1997) presented a large-deformation model for thin shells composed of elastic-plastic material. Lepik (1999) considered a bifurcation of axially loaded elastic-plastic cylindrical shells in the case of an axisymmetric buckling. Papanastasiou and Durban (1999) presented a linear bifurcation analysis for pressure-sensitive elastic-plastic hollow cylinders under radial surface loads. Dubina and Ungureanu (2000) dealt with the elastic-plastic interactive buckling of thinwalled steel compression members. Abdel-Lateef et al. (2001) presented the elastic stability analysis of a column with variable cross-section subjected to distributed and concentrated axial load. Lilkova-Markova and Dzhupanov (2001) dealt with the dynamic stability of short continuous pipes conveying liquid and supported by elastic supports. Milašinović et al. (2003) dealt with the buckling problem of steel columns using by RheologicalDynamical Analogy (RDA). Seyranian and Privalova (2003) dealt with the optimization and post-buckling 
behavior of columns elastically supported at both ends. Alvarenga and Silveira (2006) presented a study about the necessary steps to qualify a second-order inelastic analysis as an advanced one. D'Aniello et al. (2006) executed two full-scale experimental tests on the lateral load-displacement response of a Reinforced Concrete (RC) structure seismically retrofitted by buckling restrained braces. Lolov and Lilkova-Markova (2006) dealt with the dynamic stability of a curved pipe bent in the arc of a circle on the hinge supports at the ends. Fraldi et al. (2008) aimed at deriving assessment and design formulae for determining the elastic-plastic response and the ultimate compressive strength of circular concrete columns confined by the Fiber Reinforced Polymers (FRP). Sanchez and Salas (2008) dealt with seismic ground motions that cause large deformations of buried pipelines. Voyiadjis and Woelke (2008) presented a finite element model for the elastic-plastic and damage analysis of thin and thick shells. Wahrhaftig et al. (2008) evaluated a buckling critical load of bars subjected to their self-weight. Wahrhaftig et al. (2016) executed a calculation of the natural frequency of vibration and the stability verification of a slender column including the reducing effects of stiffness both of the axial force and creep. Wahrhaftig et al. (2019) executed an analytical determination of the vibration frequencies and buckling loads of slender reinforced concrete towers. Wahrhaftig et al. (2020a) evaluated a limit state of stress and strain of free-fixed columns with variable geometry according to criteria from the Brazilian code for concrete structures. Wahrhaftig et al. (2020b) did an evaluation of mathematical solutions for the determination of buckling of columns under self-weight. Wahrhaftig (2020) did a time-dependent analysis of slender, tapered reinforced concrete columns. Wahrhaftig et al. (2021) made a stress assessment in reinforcement for columns with concrete creep and shrinkage through Brazilian technical normative. Ismail (2011) provided an analysis of the dynamical behavior and stability of pipes conveying fluid. Phungpaingam et al. (2011) presented an alternative model to analyze the post-buckling behavior of a hingedhinged column made from nonlinear material (i.e., Ludwick material). Beylergil et al. (2012) studied the buckling and compressive failure of adhesively-bonded stepped-lap joints (with/without composite patches) composed of pultruded glass fiber-reinforced polymer. Abed et al. (2013) presented the Finite-Element (FE) study of the axial load capacity of pre-twisted steel bars of rectangular cross-sections. Kambe et al. (2013) proposed a sandwich panel with plywood and steel members for a new structural member. Ananthi and Anbarasu (2014) studied the possibility of using built-up cold-formed steel columns composed of two-lipped channels interconnected using a series of batten plates.
Ananthi et al. (2021) using the Finite Element Model (FEM) previously reported a parametric study, comprising 132 models, described for stainless steel battened built-up columns. Eissa et al. (2014) analyzed the work of a saturation-based active controller for vibration suppression of a four-degree-of-freedom rotorAMB system. Andreev and Tsybin (2015) gave the solution to the problem of the stability of a compressed rod with a variable cross-section.

Li et al. (2015) presented a novel scrimber composite. The attempts were made through theoretical analysis to predict the buckling stress of the column specimens under both elastic and inelastic buckling. In Fig. 9e they presented the graph of strains at mid-length of a slender column and measured by strain gauges similarly like in Fig. 4a in the book (Murawski, 2011a) and in Fig. 4 in the paper (Murawski and Kłos, 2007) and in the doctor's thesis (Murawski, 1999) as well as in Rys.2 in the paper (Murawski, 1992).

Patel et al. (2015) dealt with High-strength thinwalled Concrete-Filled Steel Tubular (CFST) columns widely used in modern composite structures that might undergo local and global buckling. Özbaşaran et al. (2015) presented an alternative design procedure for lateral-torsional buckling of the cantilever I-beams which aimed to simplify the calculation of critical loads and design moments. Al-Kamal (2016) presented the possible collapse mechanisms initiated by a precast flexural member dropping on a lower member.

Jakab et al. (2016) focused on load-bearing glass columns and also on the design, the load-bearing capacity and the stability issues of fins. In Fig. 4 they presented the graph of strains set at mid-length of a slender glass column measured by strain gauges similarly like in Fig. 4a in the book (Murawski, 2011a) and in Fig. 4 in the paper of (Murawski and Kłos, 2007) and in the doctor's thesis Murawski (1999) as well as in Rys.2 in the paper (Murawski, 1992). They described this as: "... Fig. 4 indicates the loading force vs. strains on the glass surface. At the beginning both outer surface of the glass column is in compression after that, the compression starts to decrease at one outer glass surface and tensile stresses develop. The buckling process starts during this phenomenon", i.e., is according to the Technical Stability Theory (TSTh).

Kalamara et al. (2016) executed an experimental investigation for the structural performance assessment of square hollow glass columns. Kukhar et al. (2016) formed a gradient curve of a temperature distribution of lengthwise of the billet by differentiated heating before profiling by buckling. Łukowicz et al. (2016) dealt with cold-formed steel sections as extensively affected the modern steel construction industry. Megahed (2016) dealt with steel-concrete composite columns used in modern buildings. He investigated the behavior of pin- 
ended axially and eccentrically loaded concrete encased steel composite columns. Tarsha and Takla (2016) evaluated the ultimate load of composite columns "steel-concrete" having square or circular steel tubes filled hollow section with concrete. Abbas and Awazli (2017) developed a numerical model in a threedimensional nonlinear finite element and then validated it against experimental results reported in the literature. Abdel-Karim et al. (2017) proposed a model for the strength analysis of High-Strength Concrete (HSC) columns subjected to eccentric loading. Ammash (2017) dealt with shape optimization of innovated cold-formed steel columns under uniaxial compressive loading.

Atteya et al. (2017) dealt with an axial load capacity and the stiffness of a rectangular Hollow Structural Section (HSS) of the steel tube. In Fig. 19 they presented the graphs of strains set at mid-length measured by strain gauge similarly like in Fig. 4a in the book Murawski (2011a) and in Fig. 4 in the paper (Murawski and Kłos, 2007) and in the doctor's thesis Murawski (1999) as well as in Rys. 2 in the paper Murawski (1992). Those graphs showed the way of losing stability in accordance with the Technical Stability Theory.

Baru (2017) dealt with buckling, as the most prominent failure mode of steel column stability as well as the structural stability of steel structures. Johnson et al. (2017) reported the results of a numerical and theoretical study of the buckling phenomenon in elastic columns containing a line of holes. Bedon and Amadio (2017) did a unified approach for the buckling verification of structural glass elements. Bedon and Amadio (2018) they made a buckling analysis and design proposal for 2-side supported double Insulated Glass Units (IGUs) in compression. Oliveira et al. (2017) studied the shear effect on the buckling of columns embedded in an elastic medium, evidencing the interaction of the column with the foundation. Silvestre et al. (2018) studied the influence of the nature of the deformation mode (global, local and distortional) on the load, carrying capacity of beams beyond the yield load. The five beams with different cross-sections, lengths, supports and loadings were analyzed. Słowiński and Piekarczyk (2017) dealt with a safe and economic design of steel cylindrical shells according to European Standard EN 1993-1-6 often requiring a nonlinear analysis. Abdulazeez et al. (2018) presented a numerical study on the behavior of Hollow-Core Fiber Reinforced Polymer-Concrete-Steel (HC-FCS) columns under combined axial compression and lateral loadings. Brasil and Wahrhaftig (2018) did an experimental evaluation of the effect of geometric nonlinearities on structural resonances. Can et al. (2018) designed a novel crash box as a telescopic structure by joining coaxial tubes by using gradual bonding surface areas. Isleem et al. (2018) dealt with experimental and analytical investigations of the stress-strain behavior of rectangular concrete columns externally confined with Carbon Fiber-Reinforced Polymer (CFRP) composites under axial compression loading. Lilkova-Markova and Lolov (2018) investigated the problem of loss of stability of an axially compressed column. The column was fixed at one of its ends and on transversal linear spring support at the other. Massumi et al. (2018) matched the real behavior of the RC structures constructed based on the assumed specifications of the used materials. Razdolsky (2018) focused on elastic stability analysis of battened columns and laced columns with crosswise, fir-shaped and serpentine lattices. Saeed and Eissa (2018) analyzed bifurcations of periodic motion of a horizontally supported nonlinear Jeffcott-rotor system having a transversely cracked shaft. Saeed and Eissa (2019) did a bifurcation analysis of a transversely cracked nonlinear Jeffcott-rotor system at different resonance cases. Saeed (2019) did an analysis of vibration behavior and motion bifurcation of a nonlinear asymmetric rotating shaft. Next (Saeed, 2020) did an analysis of the steady-state forward and backward whirling motion of the asymmetric nonlinear rotor system and (Saeed et al., 2020a) did a nonlinear dynamic analysis of the six-pole rotor-AMB system under two different control configurations. Later (Saeed et al., 2020b) executed an analysis of radial versus Cartesian control strategies to stabilize the nonlinear whirling motion of the six-pole rotor-AMBs and (Saeed et al., 2020c) an analysis of periodic, quasi-periodic and chaotic motions diagnose a crack on a horizontally supported nonlinear rotor system. Next, (Saeed et al., 2021a) made a sensitivity analysis and vibration control of asymmetric nonlinear rotating shaft system utilizing 4-pole AMBs as an actuator and (Saeed et al., 2021b) did an analysis of the rub-impact forces between a controlled nonlinear rotating shaft system and the electromagnet pole legs.

Slimani et al. (2018) dealt with the concept of the effective length factor of columns representing an important parameter with regard to the elastic buckling analysis. Thumrongvut and Tiwjantuk (2018) presented the experimental results on the strength and axial behavior of rectangular steel tube columns filled with Cellular Lightweight Concrete (CLC) under axial compression. Anuntasena et al. (2019) presented the 3D Finite Element (FE) analysis of the Concrete-Encased Steel (CES) columns subjected to concentric or eccentric loadings. Ivanov (2019) studied small vibrations of a cylindrical shaft caused by inertial excitation. The shaft was vertically situated. It was supported by a spherical and a cylindrical joint. Krishan et al. (2019) presented a theoretical study of the structural resistance of compressed short concrete elements in a glass-fiber reinforced shell. Kudryavtsev (2019) presented the study of the behavior of axially loaded columns that consisted of two flanges and a thin triangularly corrugated web, 
connected by automatic welding. Nazarimofrad and Shokrgozar (2019) dealt with a Buckling-Restrained Braced frame (BRB) as the seismic force-resisting system used in buildings. Nonlinear time history and incremental dynamic analysis techniques were applied to investigate the behavior of the two frames with different stories under different ground motion records.

Qi et al. (2019) dealt with the innovative pultruded Fiber Reinforced Polymer (FRP). Axial compression tests with both ends pinned were employed to investigate the columns under concentric load. Strain responses on specimens with different slenderness ratios were consistent with the observed failure modes. The courses of the values of the longitudinal strains in Fig. 10 correspond to the graph in Fig. 4 in the paper (Murawski and Kłos, 2007) and in Fig. 4a (Murawski, 2011b) - what confirms qualitatively the correctness of the Technical Stability Theory.

Roy et al. (2019) dealt with a built-up box section popular for column members in Cold-Formed Steel (CFS). Simão et al. (2019) presented a study on the buckling behavior of slender steel columns under fire conditions, which depended on two main factors: The thermal elongation of the column and the degradation of the steel mechanical properties due to temperature rise. Virgens et al. (2019) presented the experimental study of eccentrically loaded reinforced concrete columns with an added $35 \mathrm{~mm}$ self-compacting concrete jacket attached to the column's most compressed faces using wedge bolts. Zhou et al. (2019) introduced the effective length factor and imperfection factor to the current stability factor formula to calculate the ultimate load of the lattice boom accurately. Zucco et al. (2020) tested a $750 \times 640 \times 240 \mathrm{~mm}$ variable-stiffness unitized integratedstiffener out-of-autoclave thermoplastic composite wingbox for a combined shear-bending-torsion induced buckling load. Abedini et al. (2020) focused on investigating blast load parameters to design of Reinforced Concrete (RC) columns to withstand blast detonation. The numerical model was based on finite element analysis using LS-DYNA. Ahiwale et al. (2020) dealt with a Concrete-Filled Tubular (CFT) structure consisting of high strength, favorable ductility, fire resistance and energy absorption. Alomarah et al. (2020) dealt with auxetic structures that exhibit Negative Poisson's Ratio (NPR). Avci-Karatas (2020) dealt with construction in areas of high earthquake intensity, extreme climates and blast loading. Doan et al. (2020) dealt with a design of thin-walled composite columns. Goroshko et al. (2020) proposed a method of preventing the loss of Euler stability by thin rods. Kiss (2020a) investigated the planar stability of fixed-fixed shallow circular arches and (Kiss, 2020b) aimed to find the buckling loads for pinned-rotationally restrained shallow circular arches in terms of the rotational end stiffness, geometry and material distribution. Naseri et al. (2020) presented an experimental study into the buckling behavior of Glass Fabric-Reinforced Polymer (GFRP) cylindrical shells subjected to axial compression load. Pinarbasi et al. (2020) dealt with the Turkish Building Code for Steel Structures replaced with a more rational Specification of Design and Construction of Steel Structures (SDCSS), which was prepared based on the American steel design specification (AISC 360-16). Qays and Al-Zuhairi (2020) discussed the idea of using slender Reinforced Concrete (RC) columns with crossshaped (+-shaped) instead of square-shaped columns. Rajkannu and Sanjeevi (2020) presented the details of an experimental and numerical study on the effect of warping on the Flexural-Torsional Buckling (FTB) behavior of axially loaded cold-formed steel lipped channel members. Saberi et al. (2020) studied the cooperation of steel and concrete in composite columns. Saingam et al. (2020) dealt with a seismically retrofitting Reinforced Concrete (RC) building with a combination of Buckling-Restrained Braces (BRBs) and elastic steel frames that provided additional lateral stiffness and energy dissipation capacity. Terazawa et al. (2020) dealt with a grid-purlin system composed of RHS members known to be effective to prevent buckling of the welded beams. Viana et al. (2020) addressed a corotational Lagrangian formulation for nonlinear dynamic analysis of steel planar frames. Mehrabi et al. (2021) studied the dynamic response and mechanical performance of fiber-reinforced concrete columns using hybrid numerical algorithms.

Besides, there was done the literature review of semislender, thin-walled column stability (Murawski 2008a; 2008b; 2008c; 2008d; 2008e; 2020a; 2020b; 2020c).

\section{Stability of Columns in Elastic-Plastic States}

An application of thin-walled columns for structures mainly depends on their load capacity for axial loads, i.e., their stability. In the case of slender columns, this will refer to the stability in elastic states, but more often in engineering practice in the elastic-plastic states. In an analysis of stability in practical designing for squat columns, the determining of critical force may be used by a simplification formulated by (Tetmajer, 1886; Jasiński, 1894, 1985).

The simplification relies on the replacement of Euler's hyperbole by Tetmajer-Jasiński's straight line. For materials having the limit of plastic stress $\sigma_{p l}=R_{e}^{*}$ and limit of elastic stress $\sigma_{H}=R_{H}^{E u_{H}}$ the co-ordinates of Tetmajer-Jasiński's straight line are: $\sigma_{c r}=\sigma_{H}=R^{E u}{ }_{H}$ for the slenderness ratio limiting elastic states $\lambda=\lambda_{\text {el_lt }}$ (simultaneously on the Euler's hyperbole) and $\sigma_{c r}=\sigma_{p l}=$ $R_{e}^{*}$ for $\lambda=0$ and in that case, the formula of TetmajerJasiński's straight line is as follows: 


$$
\sigma_{c r}^{T-J}=R_{e}^{*}-\frac{R_{e}^{*}-R_{H}^{E u}}{\lambda_{e l_{-} l t}} \cdot \lambda,
$$

it may be also presented as depending on $\left(L^{*} t\right)$ and $A$.

For squat thin-walled cylindrical columns (Fig. 1) it is as follows:

$$
\sigma_{c r_{-} c y l i n d r}^{T-J}=R_{e}^{*}-2 \sqrt{2} \cdot \pi \cdot \frac{\left(R_{e}^{*}-R_{H}^{E u}\right)}{\lambda_{e l_{-} l t}} \cdot \frac{(L \cdot t)}{A},
$$

and for squat thin-walled square columns (Fig. 2):

$$
\sigma_{c r_{-} \text {square }}^{T-J}=R_{e}^{*}-4 \sqrt{6} \cdot \frac{\left(R_{e}^{*}-R_{H}^{E u}\right)}{\lambda_{e l_{-} l t}} \cdot \frac{(L \cdot t)}{A} .
$$

Tetmajer-Jasiński's simplification was described in the paper of (Murawski, 2008a).

The next simplification which may be used in the analysis of stability for semi-slender columns to determine the critical force in practical designing is the one formulated by Ostenfeld (1898) and Johnson.

The simplification relies on the replacement of Euler's hyperbole by Johnson-Ostenfeld's parabola.

For materials having the limit of plastic stress $\sigma_{p l}=R_{e}{ }^{*}$ the critical force $\sigma_{c r}=\sigma_{p l}=R_{e}{ }^{*}$ for $\lambda=0$ and the formula of Johnson-Ostenfeld's parabola is as follows: $\sigma_{c r}^{J-O}=R_{e}^{*}-\frac{R_{e}^{* 2}}{4 \cdot E \cdot \pi^{2}} \cdot(\lambda)^{2}$

Johnson-Ostenfeld's parabola for squat thin-walled cylinder columns depending on $\left(L^{*} t\right)$ and $A$ is as follows (Fig. 3):

$\sigma_{c r_{-} \text {cylind }}^{J-O}=R_{e}^{*}-\frac{2 \cdot R_{e}^{* 2}}{E} \cdot\left[\frac{(L \cdot t)}{A}\right]^{2}$,

and for squat thin-walled square columns (Fig. 4):

$\sigma_{c r_{-} \text {square }}^{J-O}=R_{e}^{*}-\frac{24 \cdot R_{e}^{* 2}}{\pi^{2} \cdot E} \cdot\left[\frac{(L \cdot t)}{A}\right]^{2}$.

Johnson-Ostenfeld's simplification was described in the paper Murawski (2008b).

Ylinen (1956) used the approximation of the function $E_{t}=d \sigma / d \varepsilon=E_{t}(\sigma)$ and obtained the equation:

$$
\sigma_{c r}^{\text {Ylinen }}=\frac{2 \cdot R_{e}}{1+\left(\frac{\lambda}{\pi}\right)^{2} \frac{R_{e}}{E}+\sqrt{\left(1+\left(\frac{\lambda}{\pi}\right)^{2} \frac{R_{e}}{E}\right)^{2}-4 \cdot c \cdot\left(\frac{\lambda}{\pi}\right)^{2} \frac{R_{e}}{E}}}
$$

For cylindrical columns, the critical stress according to Ylinen's formula depending on $(L * t)$ and $A$ equals (Fig. 5):

$$
\sigma_{c r_{-} y l i n d r}^{\text {Ylinen }}=\frac{2 \cdot R_{e}^{*}}{1+\left[\frac{2 \sqrt{2} \cdot(L \cdot t)}{A}\right]^{2} \frac{R_{e}^{*}}{E}+\sqrt{\left\{1+\left[\frac{2 \sqrt{2} \cdot(L \cdot t)}{A}\right]^{2} \frac{R_{e}^{*}}{E}\right\}^{2}-4 \cdot c \cdot\left[\frac{2 \sqrt{2} \cdot(L \cdot t)}{A}\right]^{2} \frac{R_{e}^{*}}{E}}}
$$

and for square columns (Fig. 6) is equal to:

$$
\sigma_{c r_{-} \text {square }}^{\text {Ylinen }}=\frac{2 \cdot R_{e}^{*}}{1+\left[\frac{4 \sqrt{6} \cdot(L \cdot t)}{\pi \cdot A}\right]^{2} \frac{R_{e}^{*}}{E}+\sqrt{\left\{1+\left[\frac{4 \sqrt{6} \cdot(L \cdot t)}{\pi \cdot A}\right]^{2} \frac{R_{e}^{*}}{E}\right\}^{2}-4 \cdot c \cdot\left[\frac{4 \sqrt{6} \cdot(L \cdot t)}{\pi \cdot A}\right]^{2} \frac{R_{e}^{*}}{E}}}
$$

Ylinen's theory was described in the paper of (Murawski, 2008c).

Březina (1966) used the function $\sigma(\varepsilon)$ according to the DIN 4114 standard and obtained the equation:

$$
\sigma_{c r}^{\text {Brzezina }}=\frac{1}{2}\left\{\left[2 R_{x}-\frac{\left(R_{e}-R_{x}\right)^{2}}{E \cdot\left(\frac{\pi}{\lambda}\right)^{2}}\right]+\sqrt{\left[2 R_{x}-\frac{\left(R_{e}-R_{x}\right)^{2}}{E \cdot\left(\frac{\pi}{\lambda}\right)^{2}}\right]^{2}-4 \cdot\left[R_{x}^{2}-\left(R_{e}-R_{x}\right)^{2}\right]}\right\}
$$




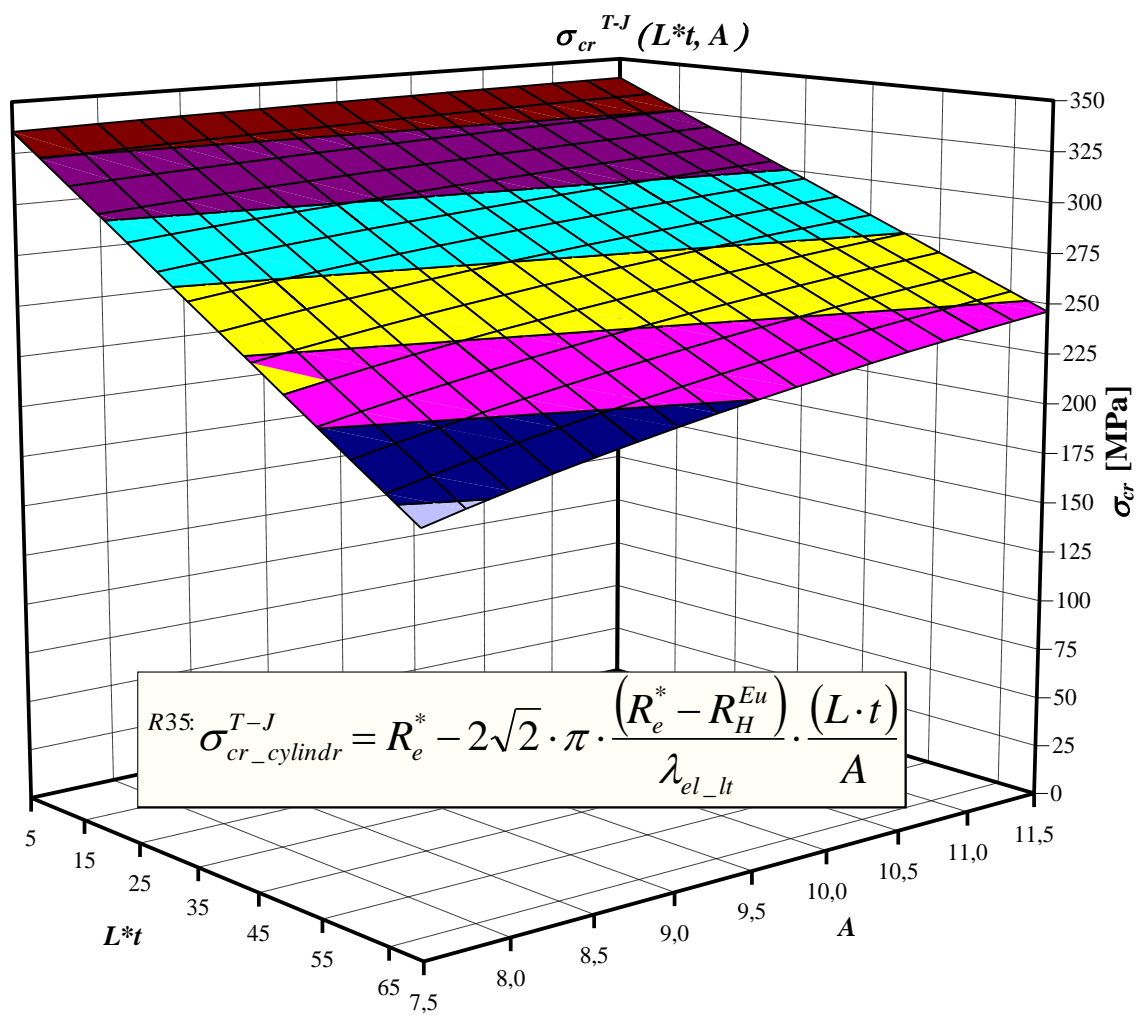

Fig. 1: Surface function $\sigma_{c r}{ }^{T-J} c y l i n\left(L^{*} t, A\right)$ based on the Tetmajer-Jasiński formula of the cylindrical columns made of steel R35

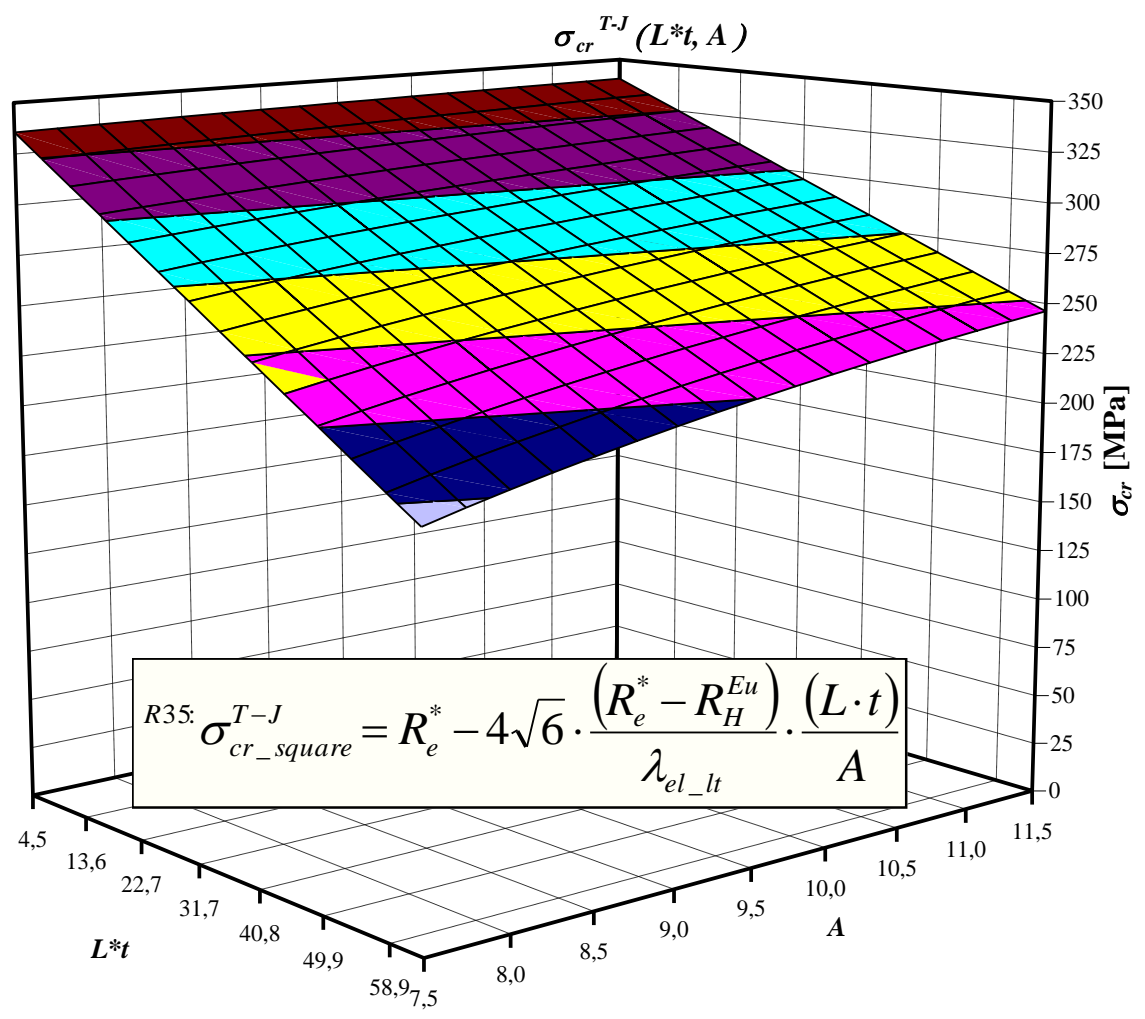

Fig. 2: Surface function $\sigma_{c r}{ }^{T-J}$ square $(L * t, A)$ based on the Tetmajer-Jasiński formula of the square-shaped columns made of steel R35 


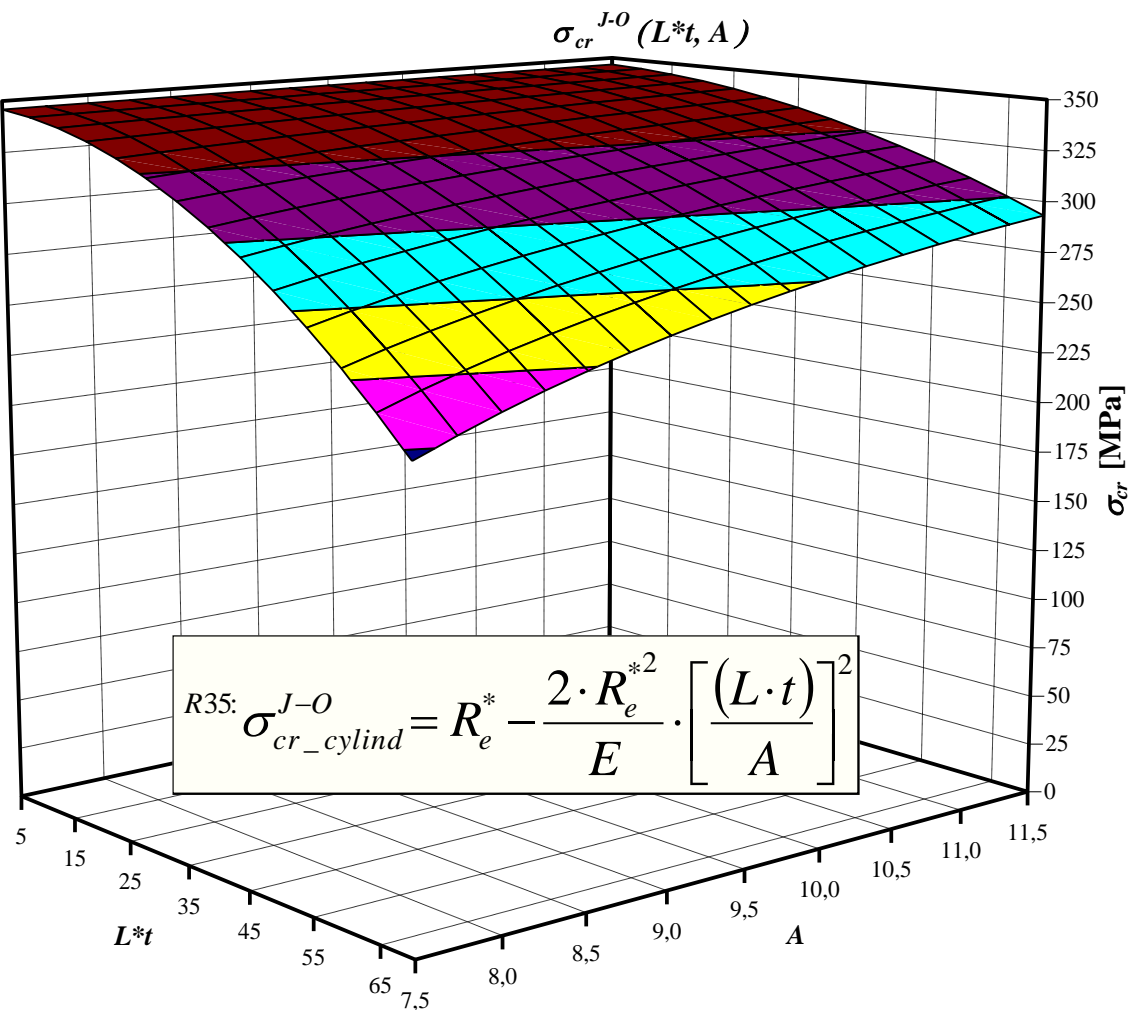

Fig. 3: Surface function $\sigma_{c r}{ }^{J-O} c y l i n(L * t, A)$ based on the Johnson-Ostenfeld formula of the cylindrical columns made of steel R35

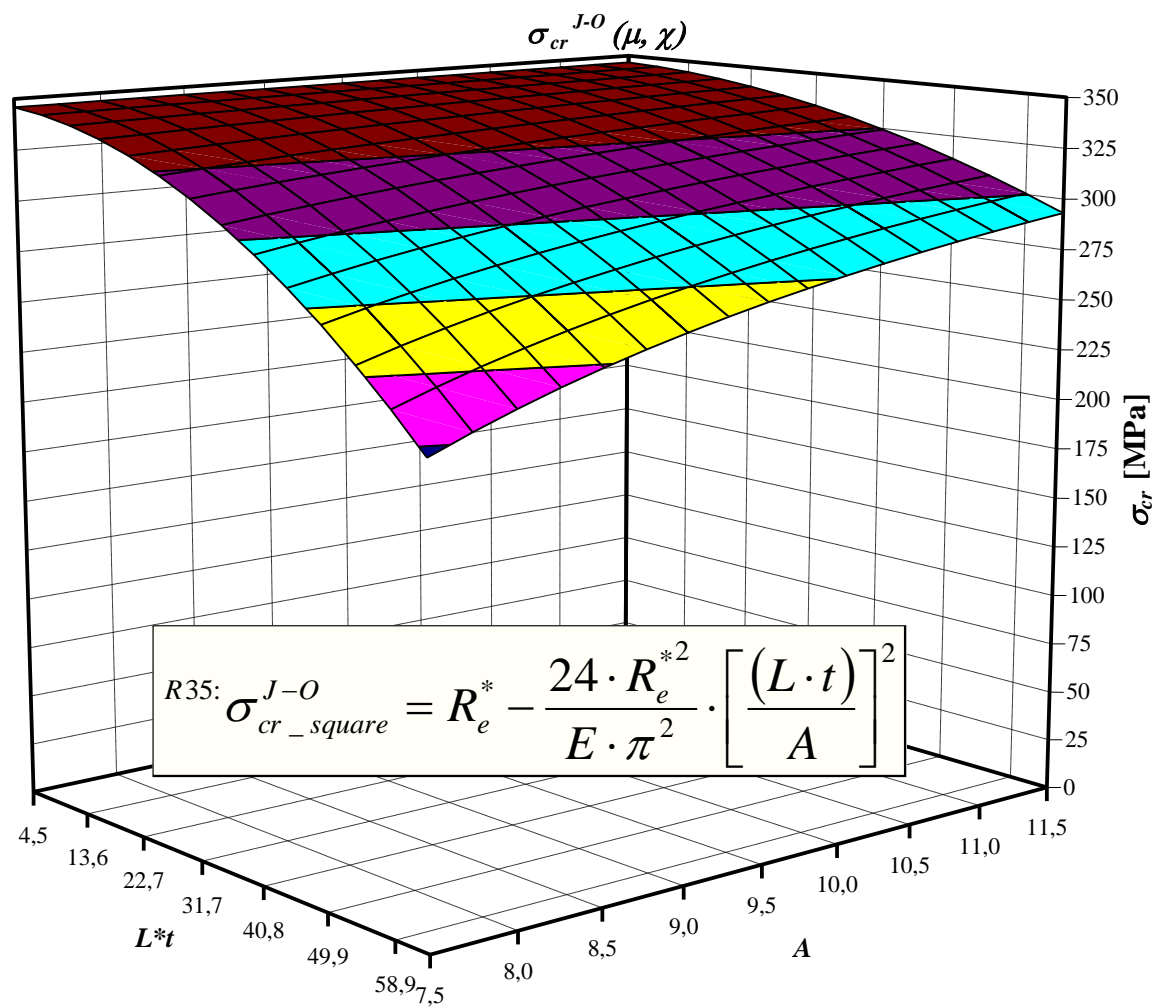

Fig. 4: Surface function $\sigma_{c r}{ }^{J-O}$ square $(L * t, A)$ based on the Johnson-Ostenfeld formula of the square columns made of steel R35 


$$
\sigma_{c r}^{\text {Ylinen }}(L * t, A)
$$

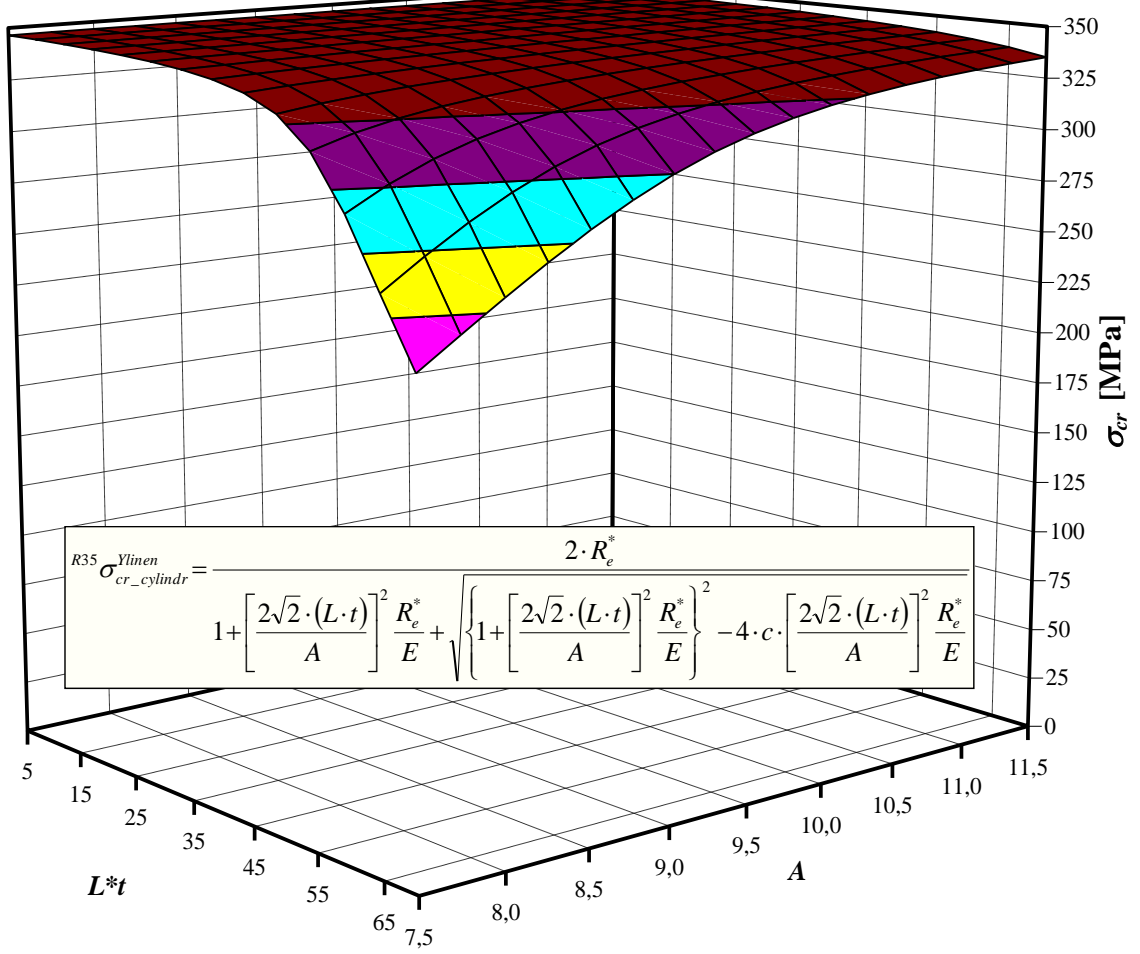

Fig. 5: Surface function $\sigma_{c r}^{\text {Ylinen }}{ }_{c y l i n}\left(L^{*} t, A\right)$ based on the Ylinen's formula of the cylindrical shaped columns made of steel R35

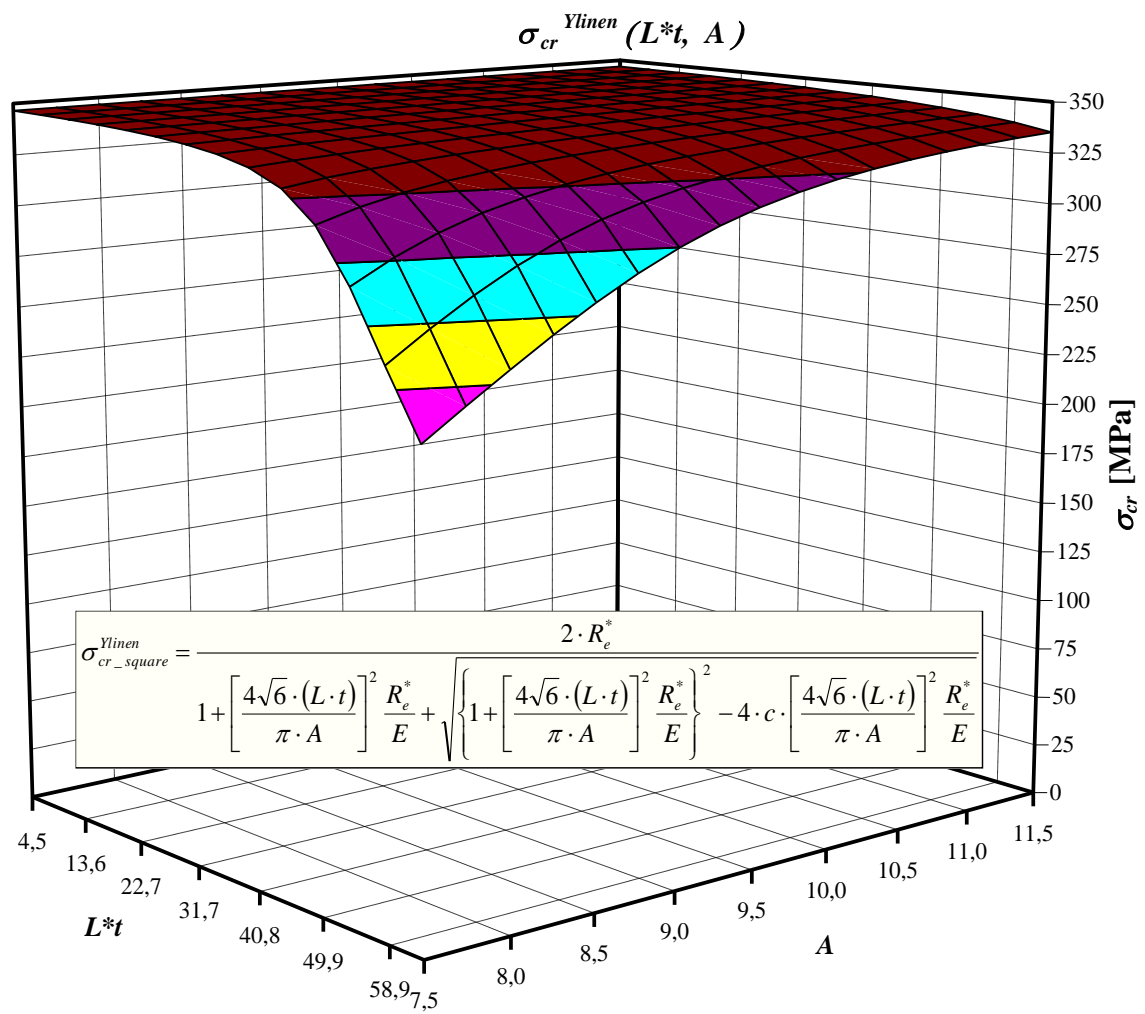

Fig. 6: Surface function $\sigma_{c r}^{\text {Ylinen }}{ }_{\text {square }}(L * t, A)$ based on the Ylinen's formula of the square columns made of steel R35 
For cylindrical columns the critical stress according to Březina (Fig. 7):

$$
\begin{aligned}
& \sigma_{c r_{-} \text {cylindr }}^{\text {Breina }}=\frac{1}{2}\left\{\left[2 R_{H}^{E u}-\frac{\left(R_{e}^{*}-R_{H}^{E u}\right)^{2}}{E}\left[\frac{2 \sqrt{2} \cdot(L \cdot t)}{A}\right]^{2}\right]\right. \\
& \left.+\sqrt{\left[2 R_{H}^{E u}-\frac{\left(R_{e}^{*}-R_{H}^{E u}\right)^{2}}{E}\left[\frac{2 \sqrt{2} \cdot(L \cdot t)}{A}\right]^{2}\right]^{2}-4 \cdot\left[R_{H}^{E u 2}-\left(R_{e}^{*}-R_{H}^{E u}\right)^{2}\right]}\right\} .
\end{aligned}
$$

For the square columns, the critical stress according to Březina depending on $\left(L^{*} t\right)$ and $A$ is equal to (Fig. 8):

$$
\begin{aligned}
& \sigma_{\text {cr-square }}^{\text {Breina }}=\frac{1}{2}\left\{\left[2 R_{H}^{E u}-\frac{\left(R_{e}^{*}-R_{H}^{E u}\right)^{2}}{E}\left[\frac{4 \sqrt{6} \cdot(L \cdot t)}{\pi \cdot A}\right]^{2}\right]\right. \\
& +\sqrt{\left.\left[2 R_{H}^{E u}-\frac{\left(R_{e}^{*}-R_{H}^{E u}\right)^{2}}{E}\left[\frac{4 \sqrt{6} \cdot(L \cdot t)}{\pi \cdot A}\right]^{2}\right]^{2}-4 \cdot\left[R_{H}^{E u 2}-\left(R_{e}^{*}-R_{H}^{E u}\right)^{2}\right]\right\}}
\end{aligned}
$$

Březina's hypothesis was described in the paper of (Murawski, 2008d).

Pearson (1950; Bleich, 1952; Vol'mir, 1965) employed in their research the combination of the tangent modulus $E_{t}$ and the modulus $E$. Using the function $\sigma(\varepsilon)$ according to the standard DIN 4114, they obtained the formula as follows:

$$
\sigma_{c r}^{\text {Pearson-Blech-Vol'mir }}=\frac{R_{x}+\sqrt{R_{x}^{2}-\left[\frac{\left(R_{e}-R_{x}\right)^{2} \lambda^{4}}{\pi^{4} \cdot E^{2}}+1\right] \cdot\left[R_{x}^{2}-\left(R_{e}-R_{x}\right)^{2}\right]}}{\left[\frac{\left(R_{e}-R_{x}\right)^{2} \lambda^{4}}{\pi^{4} \cdot E^{2}}+1\right]} .
$$

For the cylindrical columns, the critical stress according to Pearson-Bleich-Vol'mir's formula depending on $\left(L^{*} t\right)$ and $A$ is equal to (Fig. 9):

$$
\sigma_{c r_{-} \text {- } y \text { Vlinder }}^{\mathrm{P}-\mathrm{V}}=\frac{R_{H}^{E u}+\sqrt{R_{x}{ }^{2}-\left[\frac{\left(R_{e}^{*}-R_{H}^{E u}\right)^{2} \cdot 64 \cdot(L \cdot t)^{4}}{A^{4} \cdot E^{2}}+1\right] \cdot\left[R_{H}^{E H}-\left(R_{e}^{*}-R_{H}^{E H}\right)^{2}\right]}}{\left[\frac{\left(R_{e}^{*}-R_{H}^{E u}\right)^{2} \cdot 64 \cdot(L \cdot t)^{4}}{A^{4} \cdot E^{2}}+1\right]}
$$

and for the square columns (Fig. 10):

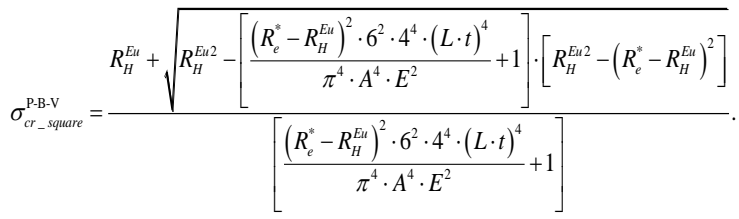

The loss stability theory of axially compressed slender columns in elastic-plastic states, based on the concept of the tangent modulus, was formulated by (Engesser, 1889; 1895; Kármán, 1908; 1910; Shanley, 1947).

Engesser-Kármán-Shanley's theory with the author's analysis of stability of thin-walled columns was described in the papers and books: Murawski (1999; 2002a; 2002b; 2003; 2008e; 2011a; 2011b; 2011c; 2017a; 2018).

In the case of stability of columns in elastic-plastic states, the author assumed that the loss of stability occurs already at minimum loads, whereas the position of the resultant neutral layer is changing what was caused by the superposition of pure compression and bending of the central line of the column.

This author's theory can be also named as the modified Engesser-Kármán-Shanley's theory and was described in the books: Murawski (2008e; 2011a; 2011b; 2011c; 2017a; 2018)

According to the assumption the state of stresses in the critical cross-section after the loss of stability and before the loss of carrying capacity results from the superposition of pure compression and bending. The formulas for the modified Engesser-Kármán-Shanley’s critical stress are as follows:

$$
\begin{aligned}
& \sigma_{H}^{K M}(\lambda)=R_{H}^{E u}+\left(1-\frac{\lambda}{\pi} \sqrt{\frac{R_{H}^{E u}}{E}}\right)\left[R_{H}^{*}-R_{H}^{E u}\right], \\
& \sigma_{c r}^{K M}(\lambda)=\left(1-\frac{\lambda}{\pi} \sqrt{\frac{R_{H}^{E u}}{E}}\right)\left(R_{e}^{*}+R_{H}^{*} \frac{\lambda}{\pi} \sqrt{\frac{R_{H}^{E u}}{E}}\right)+\frac{1}{E}\left(\frac{\lambda}{\pi} R_{H}^{E u}\right)^{2} .
\end{aligned}
$$

In the case of cylindrical columns according to the Engesser-Kármán-Shanley modified theory, the formula for the stress limiting elastic states is as (Fig. 12):

$\sigma_{H_{-} \text {cylinder }}^{K M}=R_{H}^{E u}+\left[1-\frac{2 \sqrt{2} \cdot \pi \cdot(L \cdot t)}{\lambda_{\text {el_lt }} \cdot A}\right] \cdot\left[R_{H}^{*}-R_{H}^{E u}\right]$

and the critical stress (Fig. 11):

$$
\begin{aligned}
& \sigma_{c r_{-} \text {cylinder }}^{K M}=R_{H}^{E u}+\left[1-\frac{2 \sqrt{2} \cdot \pi \cdot(L \cdot t)}{\lambda_{e l_{-} l t} \cdot A}\right] \cdot\left[R_{H}^{*}-2 R_{H}^{E u}+R_{e}^{*}\right] \\
& +\left[1-\frac{2 \sqrt{2} \cdot \pi \cdot(L \cdot t)}{\lambda_{e l_{-} l t} \cdot A}\right]^{2}\left[R_{H}^{*}-R_{H}^{E u}\right]
\end{aligned}
$$




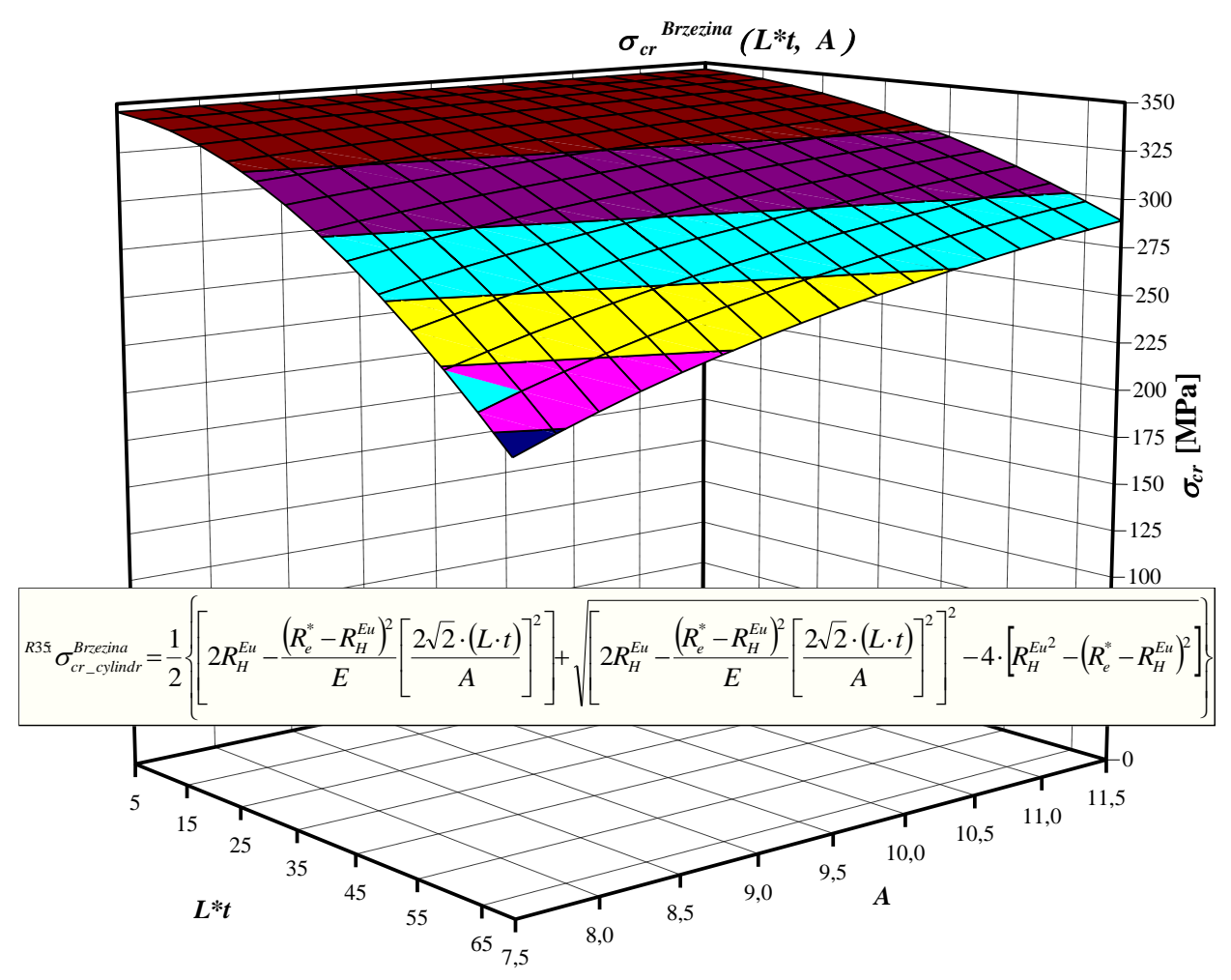

Fig. 7: Surface function $\sigma_{c r}{ }^{\text {Brezina }}{ }_{c y l i n}(L * t, A)$ based on the Březina's formula of the cylindrically-shaped columns made of steel R35

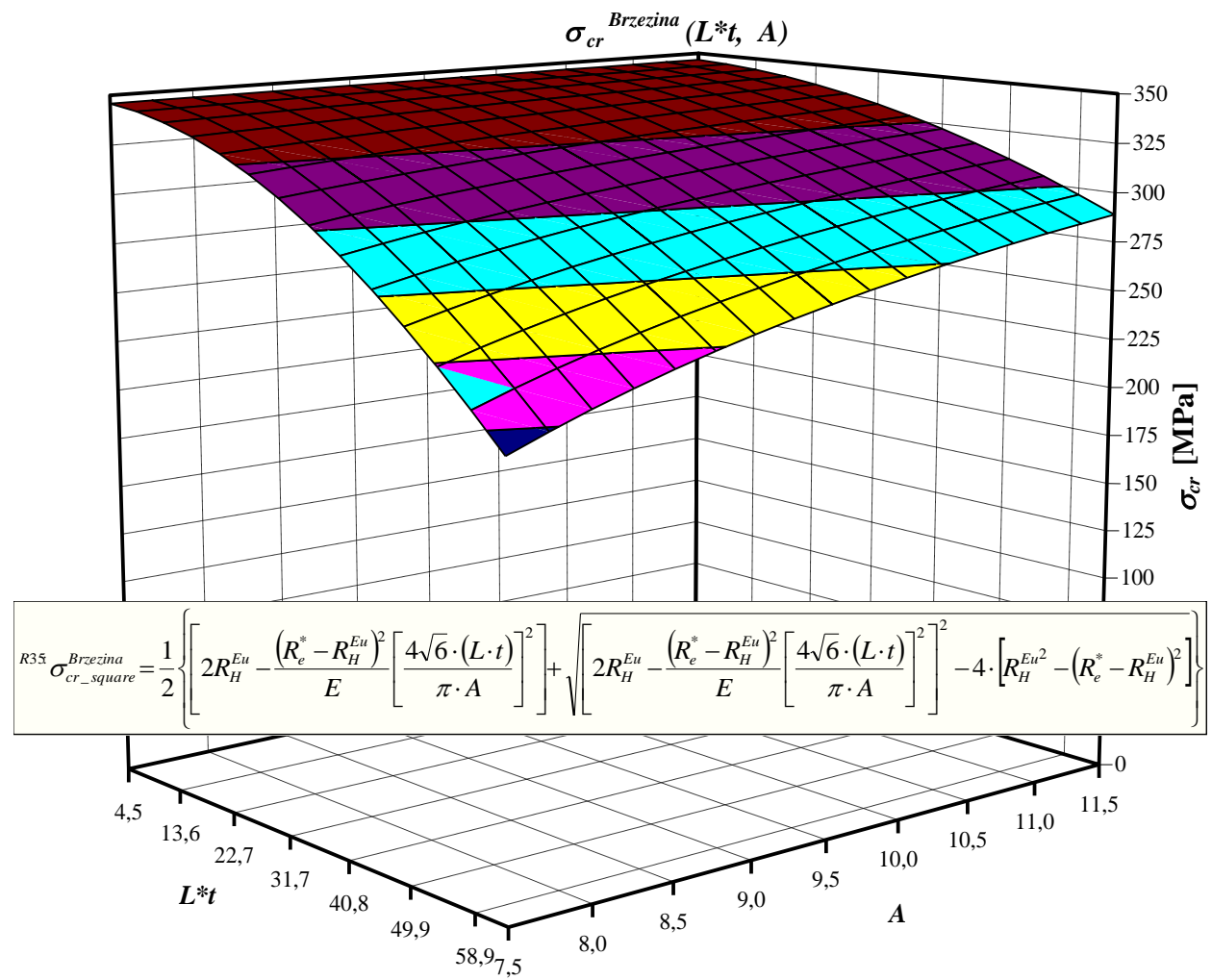

Fig. 8: Surface function $\sigma_{c r}^{\text {Brezina }}$ square $\left(L^{*} t, A\right)$ based on the Březina's formula of the square-shaped columns made of steel R35 


$$
\sigma_{c r}^{P-B-V}(L * t, A)
$$

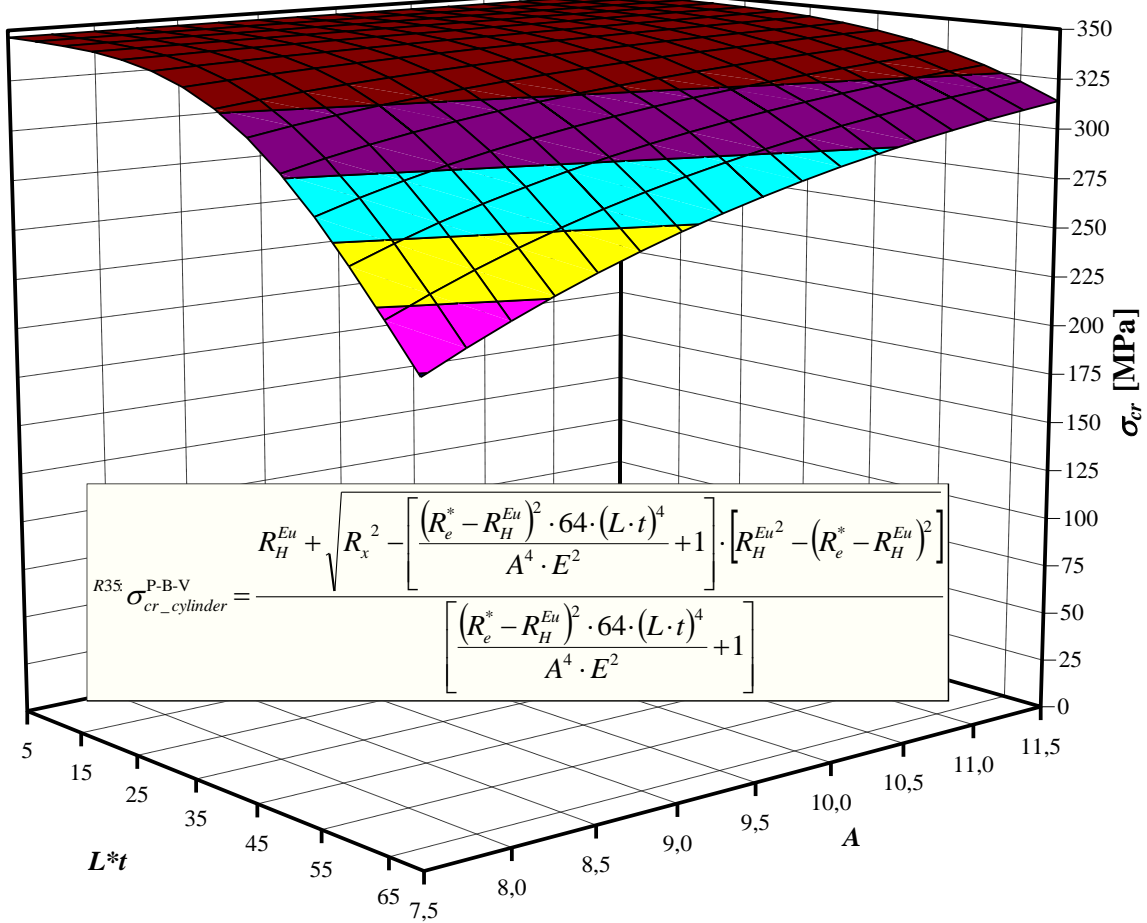

Fig. 9: Surface function $\sigma_{c r}^{P-B-V}{ }_{c y l i n}\left(L^{*} t, A\right)$ based on the Pearson-Bleich-Vol'mir's formula of the cylindrical columns made of steel R35

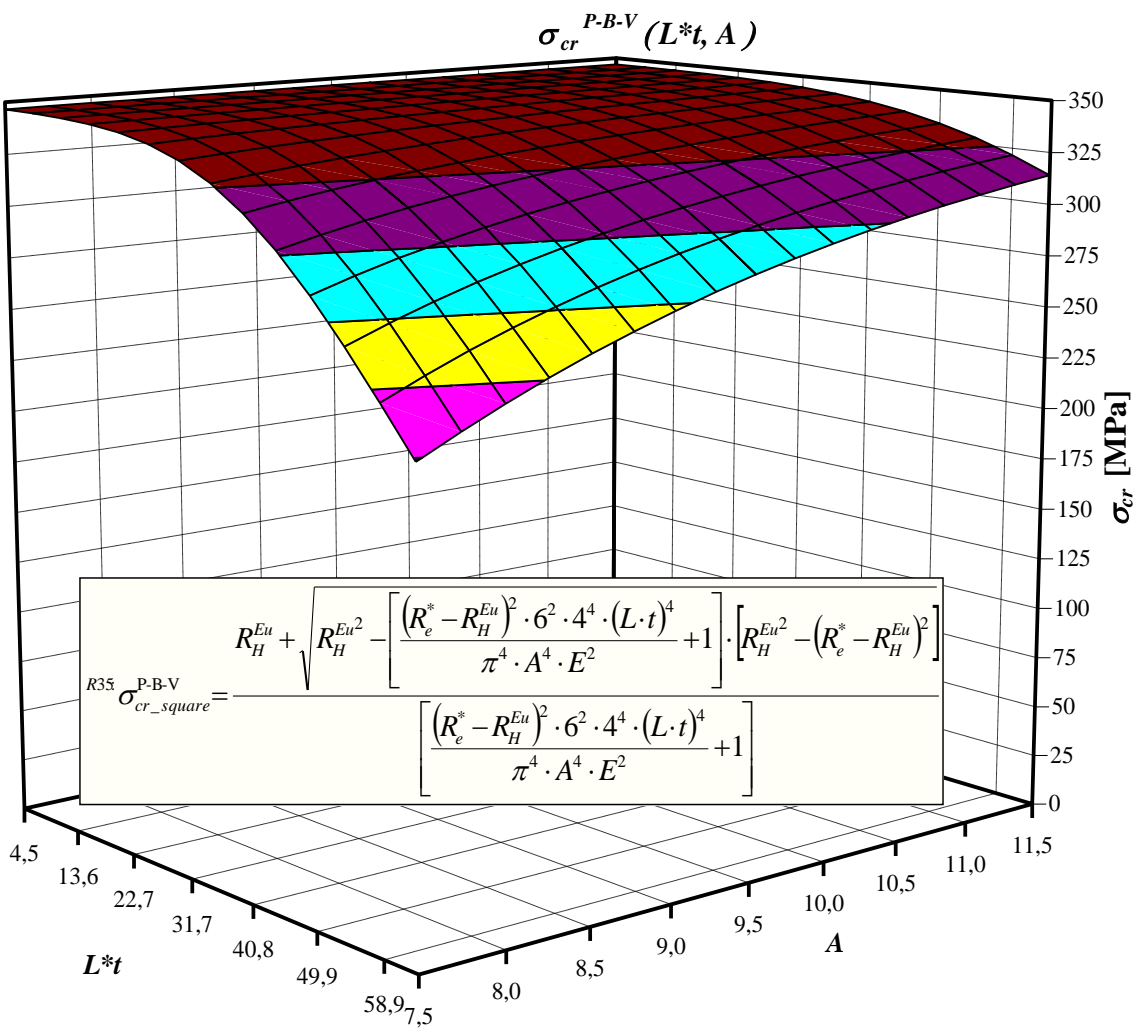

Fig. 10: Surface function ${\sigma_{c r}}^{P-B-V}$ square $\left(L^{*} t, A\right)$ based on the Pearson-Bleich-Vol'mir's formula of the square columns made of steel R35 


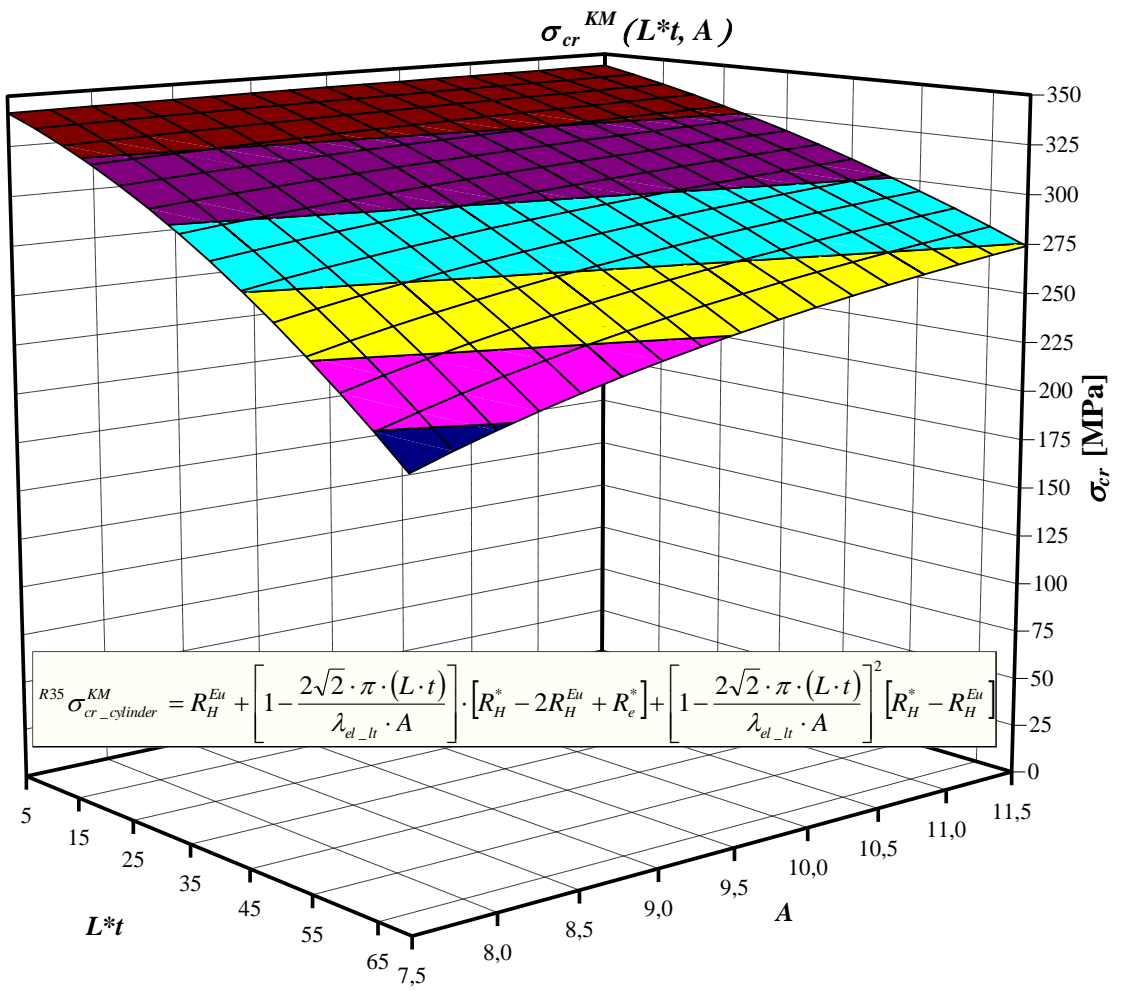

Fig. 11: Surface function $\sigma_{c r}{ }^{K M}{ }_{c y l i n}\left(L^{*} t, A\right)$ based on the modified Engesser-Kármán-Shanley’s formula of the cylindrical columns made of steel R35

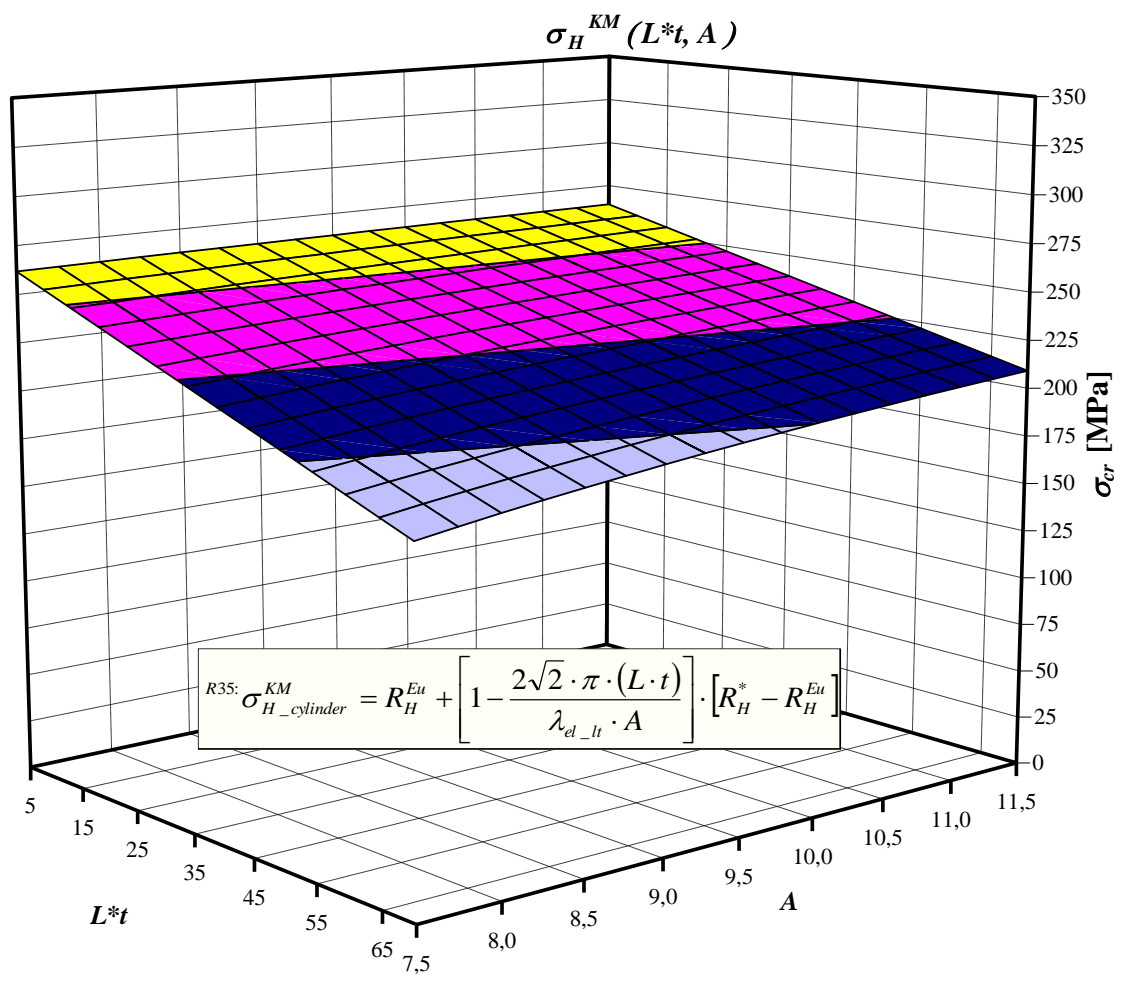

Fig. 12: Surface function $\sigma_{H}{ }^{K M}$ cylin $\left(L^{*} t, A\right)$ based on the modified Engesser-Kármán-Shanley’s formula of the cylindrical columns made of steel R35 


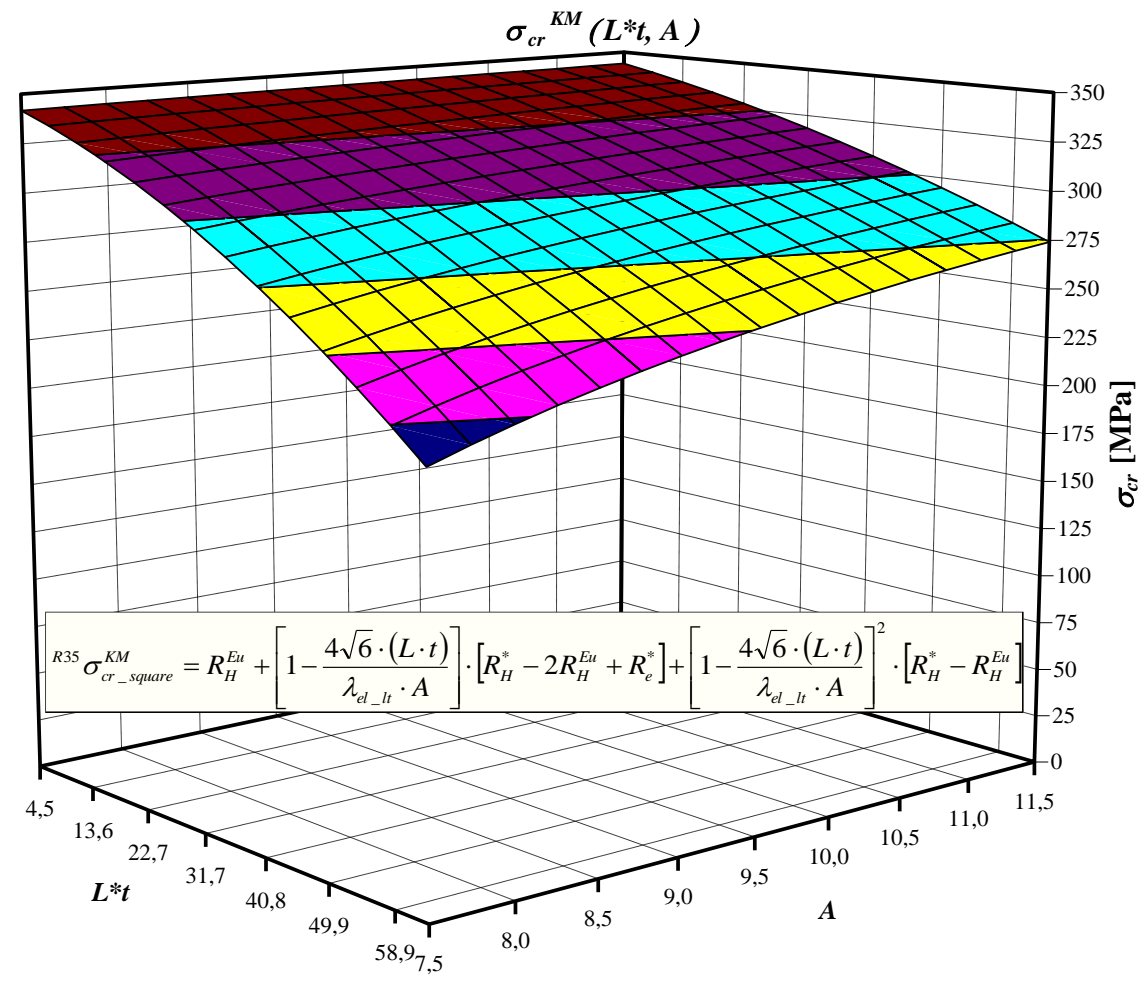

Fig. 13: Surface function $\sigma_{c r}{ }^{K M}$ square $(L * t, A)$ based on the modified Engesser-Kármán -Shanley’s formula of the square columns made of steel R35

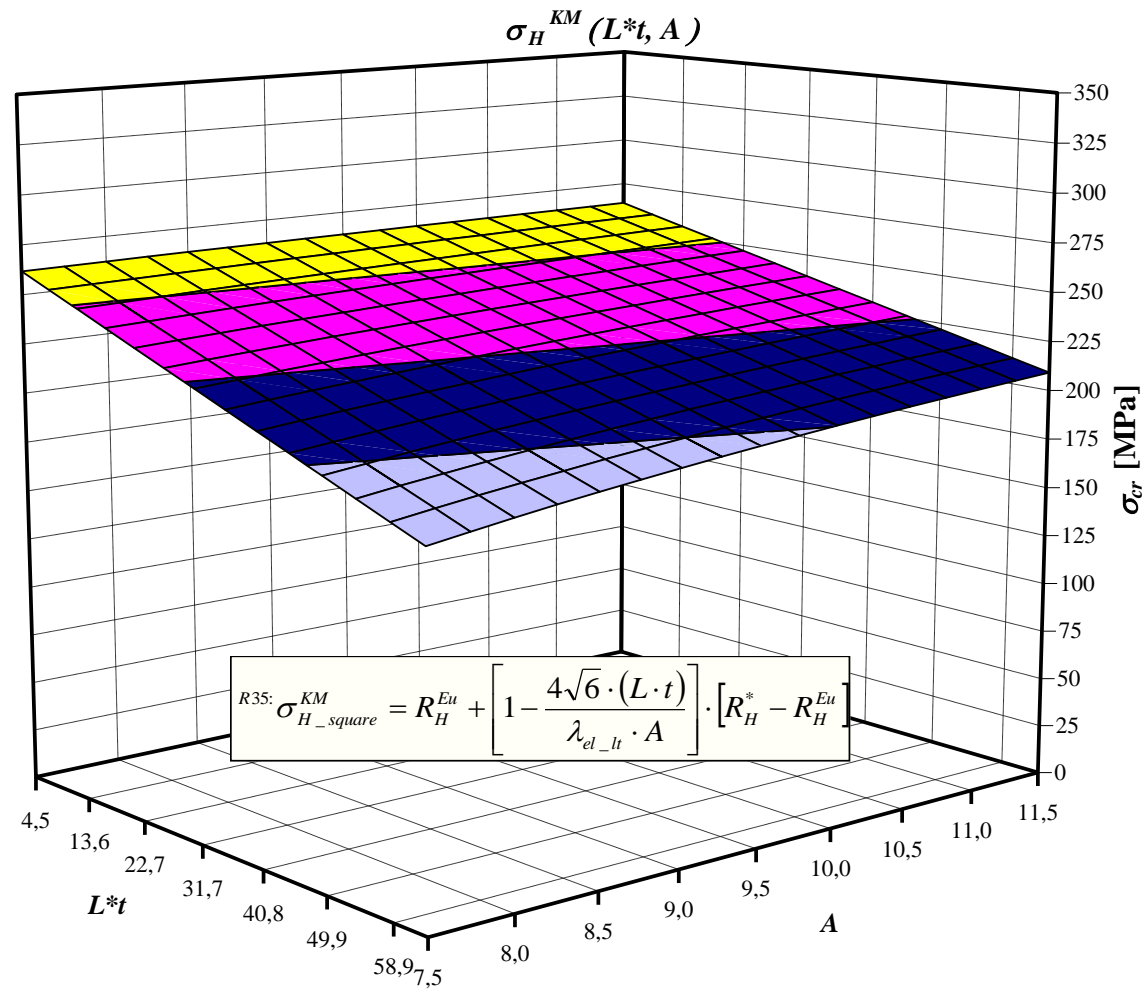

Fig. 14: Surface function $\sigma_{H}^{K M}$ square $(L * t, A)$ based on the modified Engesser-Kármán-Shanley’s formula of the square columns made of steel R35 
In the case of an axially compressed square column by ball-and-socket joints, the elastic stress is as follows (Fig. 14):

$\sigma_{H_{-} \text {square }}^{K M}=R_{H}^{E u}+\left[1-\frac{4 \sqrt{6} \cdot(L \cdot t)}{\lambda_{\text {el_lt }} \cdot A}\right] \cdot\left[R_{H}^{*}-R_{H}^{E u}\right]$,

and the critical stress (Fig. 13):

$$
\begin{aligned}
& \sigma_{c r_{-} \text {square }}^{K M}=R_{H}^{E u}+\left[1-\frac{4 \sqrt{6} \cdot(L \cdot t)}{\lambda_{e l_{-} l t} \cdot A}\right] \cdot\left[R_{H}^{*}-2 R_{H}^{E u}+R_{e}^{*}\right] \\
& +\left[1-\frac{4 \sqrt{6} \cdot(L \cdot t)}{\lambda_{e l_{-} l t} \cdot A}\right]^{2} \cdot\left[R_{H}^{*}-R_{H}^{E u}\right] .
\end{aligned}
$$

\section{Experimental Research Works on Stability in Elastic-Plastic States of Columns Compressed Through Ball-and-Socket Joints with Friction}

The tests of compression of specimens by applying an axial load through the steel ball-and-socket joints with friction (Fig. 15) were carried out using the test machine ZD 40 with the range of $40 \mathrm{kN}$. As the results of tests of the compressions of the specimens made of the same material were obtained the curves $P(\Delta a)$.

The curve obtained for a semi-slender column in the elastic-plastic states together with the type of the deformations is schematically presented in Fig. 16.

In order to show the differences in Fig. 17 is schematically presented the curve for a very slender column in elastic states, for which there are no latest deformations after relief a load.

Photo. 1 shows the specimen made of steel R35 with the cross-section $\phi 28 \times 1$ and the slenderness ratio $\lambda=$ 15 , compressed through ball-and-socket joints with so big partition of friction in the bottom joint, that part of the fold had appeared not in the middle of the column but at the upper end.

On the base of the experimental results executed on specimens made of steel R35 compressed through balland-socket joints with friction (Murawski, 1999; 2003; 2011c; 2017a) were determined the compress modulus $E_{c}$ and secant compress modulus $E_{s c}$ for thin-walled columns in elastic-plastic states (Fig. 16). They were determined analogically to Young's modulus $E$, tangent modulus $E_{t}$ and secant modulus $E_{s}$ during tension (Fig. 18). On the basis of the experimental results were determined the approximated functions: $\Delta L(\lambda)$ and $\varepsilon(\lambda)$ (Fig. 21 and 23), $P(\lambda)$ and $\sigma(\lambda)$ (Fig. 22, 24, 26 and 27) as well as $E_{c}(\lambda)$ and $E_{s c}(\lambda)$ (Fig. 25).

The approximated experimental functions $\sigma^{\exp }(\lambda)$ were compared to the theoretical functions $\sigma^{K M}(\lambda)$ - Fig. 27.

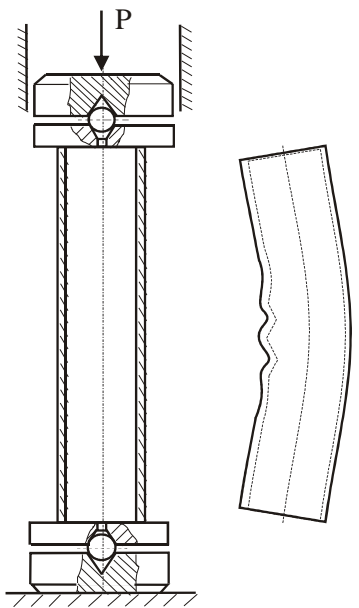

Fig. 15: Guidance and the fixing of the specimen during the compression through ball-and-socket joints with friction and the characteristic form of lateral buckling of the semi-slender cylindrical column in elasticplastic states (Murawski, 2011a; 2011b; 2017a; 2020a)

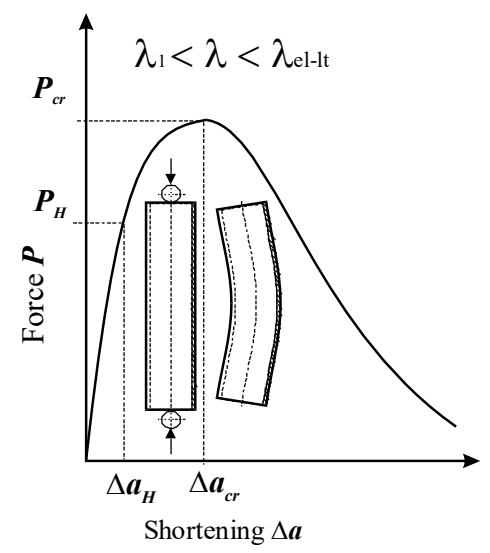

Fig. 16: Curve $P(\Delta a)$ of $\lambda_{1}<\lambda<\lambda_{e l-l t}$ in the elastic-plastic states (Murawski, 2011a; 2011b; 2017a)

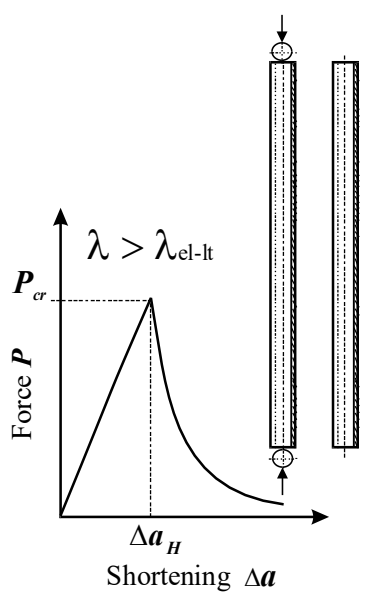

Fig. 17: Curve $P(\Delta a)$ of $\lambda>\lambda_{\text {el-lt }}$ in the elastic state (Murawski, 2011a; 2011b; 2017a) 


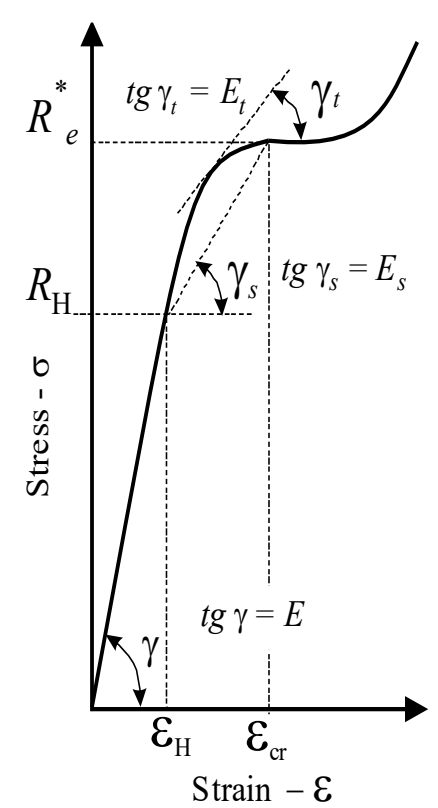

Fig. 18: Young's modulus $E$, tangent modulus $E_{t}$ and secant modulus $E_{s}$ during tension (Murawski, 2002a; 2002b; 2011a; 2011b; 2017a)

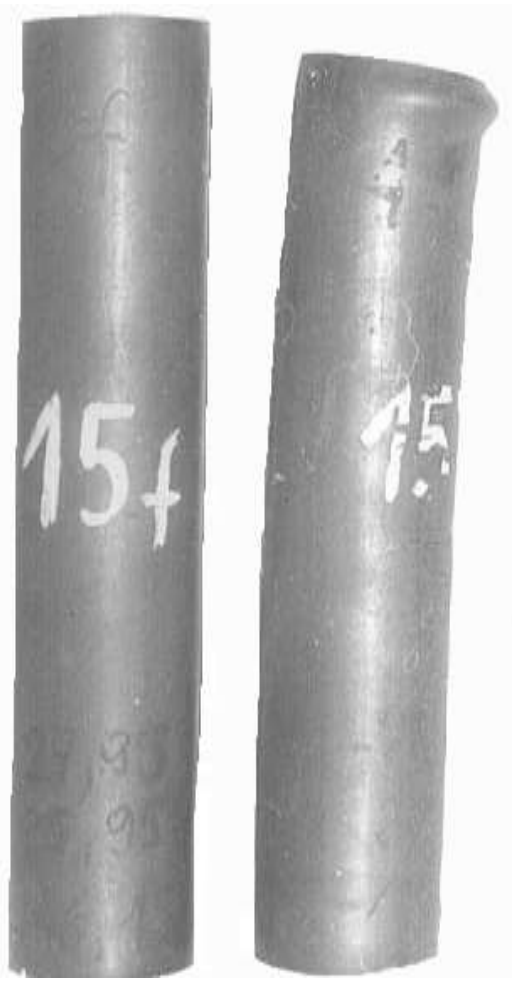

Photo 1: Specimen with the cross-section $\phi 28 \times 1$ and the slenderness ratio $\lambda=15$, made of steel R35, compressed through ball-and-socket joints with the big partition of friction in the bottom joint (Murawski, 1999; 2011b; 2017a)

\section{Discussion}

The Tetmajer-Jasiński's surface functions (2) and (3) showed in Figs. 1 and 2 are almost linearly increasing with the transverse cross-section area $A$ and strongly linearly decreasing with the $L * t$ product.

The Johnson-Ostenfeld's surface functions (5) and (6) showed in Figs. 3 and 4 are non-linearly increasing with the transverse cross-section area $A$ and strongly non-linearly with second degree decreasing with the $L * t$ product.

The Ylinen's surface functions (8) and (9) showed in Figs. 5 and 6 are strong non-linear of increasing with the transverse cross-section area $A$ and very strong parabolic non-linearly decreasing with the $L^{*} t$ product, so big part of the surface functions are almost flat.

The Březina's surface functions (11) and (12) showed in Figs. 7 and 8 are non-linearly increasing with the transverse cross-section area $A$ and strongly non-linearly with second degree decreasing with the $L * t$ product.

The Pearson-Bleich-Vol'mir's surface functions (14) and (15) showed in Fig. 9 and 10 are non-linearly increasing with the transverse cross-section area $A$ and strongly parabolic non-linearly with second degree decreasing with the $L^{*} t$ product.

The author's surface functions (18) and (20) for the limiting elastic stress showed in Figs. 12 and 14 are linearly decreasing with the $L^{*} t$ product and linearly increasing the transverse cross-section area $A$, so the surface functions are flat.

The author's surface functions (19) and (21) for the critical compressive stress showed in Fig. 11 and 13 are slightly non-linearly decreasing with the $L * t$ product and slightly non-linearly increasing with the transverse cross-section area $A$, so a part of the surface function is almost flat.

In order to compare the experimental results to the results obtained from simplifications and hypotheses the results in the case of columns with the transverse cross-section $\phi 50 \times 1$ and $\phi 28 \times 1$ made of the steel R35 were determined and showed for adequately ranges for elastic-plastic states as the graphs of the functions $\sigma_{c r}(\lambda)$ in Figs. 27-33.

The maximal departures from the experimental results of those obtained from simplifications and hypotheses are presented in Table 1 and 2 .

The biggest maximal differences are between the experimental results and Ylinen's: -69,90 MPa and -21,63\% for $\phi 50 \times 1$ and $-68,93 \mathrm{MPa}$ and $-25,94 \%$ for $\phi 28 \times 1$.

The least maximal differences are between the experimental results and the author's approximated hypothesis: 7,06 $\mathrm{MPa}$ and 2,41\% for $\phi 50 \times 1$ and $-5,21$ MPa and $-2,01 \%$ for $\phi 28 \times 1$.

For the columns $\phi 50 \times 1$ on the base of the tests were assumed: $E^{*}=195533 \mathrm{MPa}, \lambda_{\text {el-lt }}=102.69, R_{e}{ }^{*}=358.56$ $\mathrm{MPa}, R_{H}{ }^{*}=247,34 \mathrm{MPa}, R_{H}{ }^{E u}=202.875 \mathrm{MPa}$. 

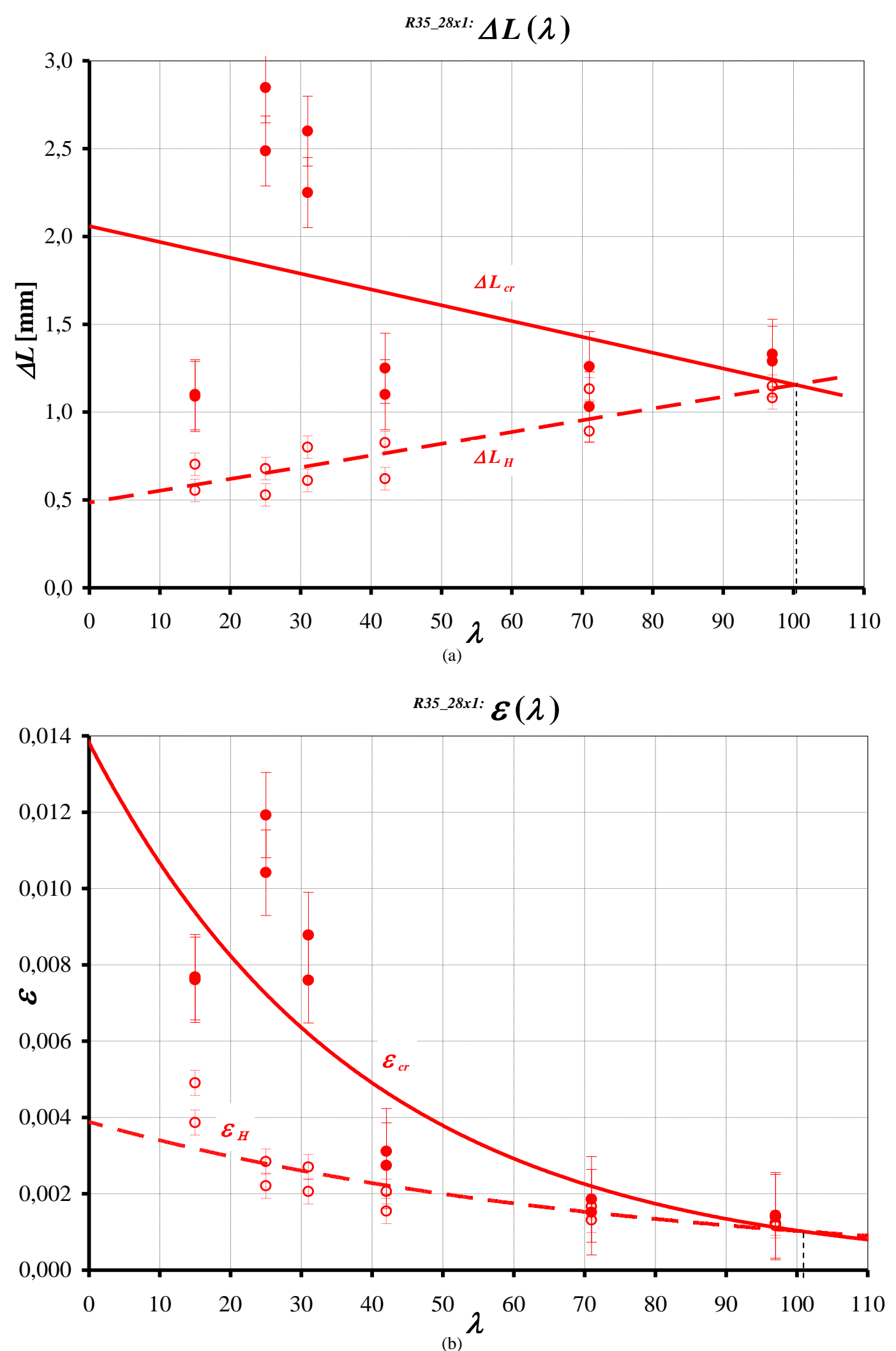

Fig. 21: Approximated functions: (a) $\Delta L(\lambda)$ and (b) $\varepsilon(\lambda)$ of the specimens with cross-section $\phi 28 x 1$ made of steel R35, compressed through ball-and-socket joints with friction 
Krzysztof Murawski / International Journal of Structural Glass and Advanced Materials Research 2021, Volume 5: 82.114
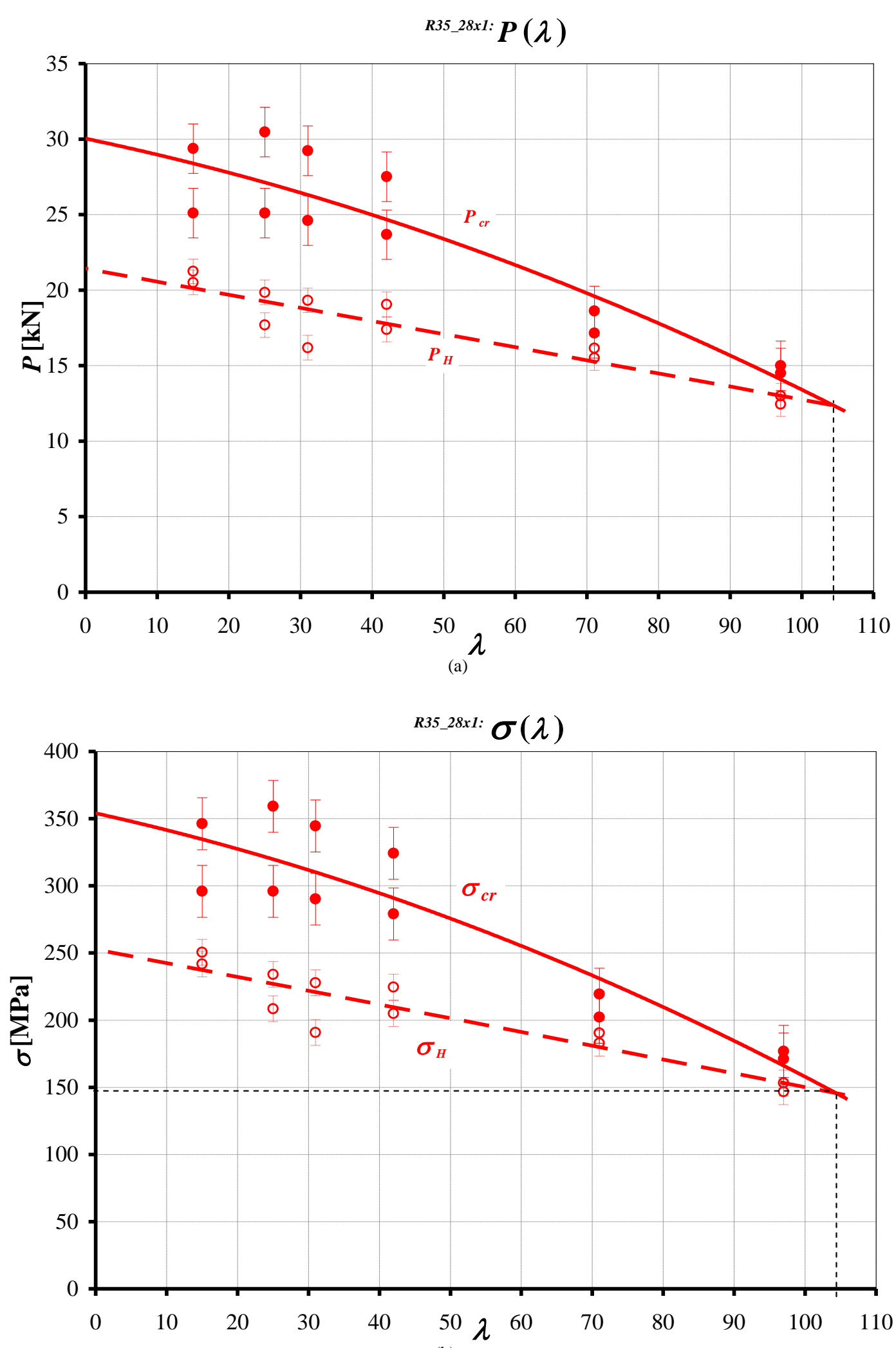

(b)

Fig. 22: Approximated functions: (a) $P(\lambda)$ and (b) $\sigma(\lambda)$ of the specimens with cross-section $\phi 28 \times 1$ made of steel R35, compressed through ball-and-socket joints with friction 
Krzysztof Murawski / International Journal of Structural Glass and Advanced Materials Research 2021, Volume 5: 82.114
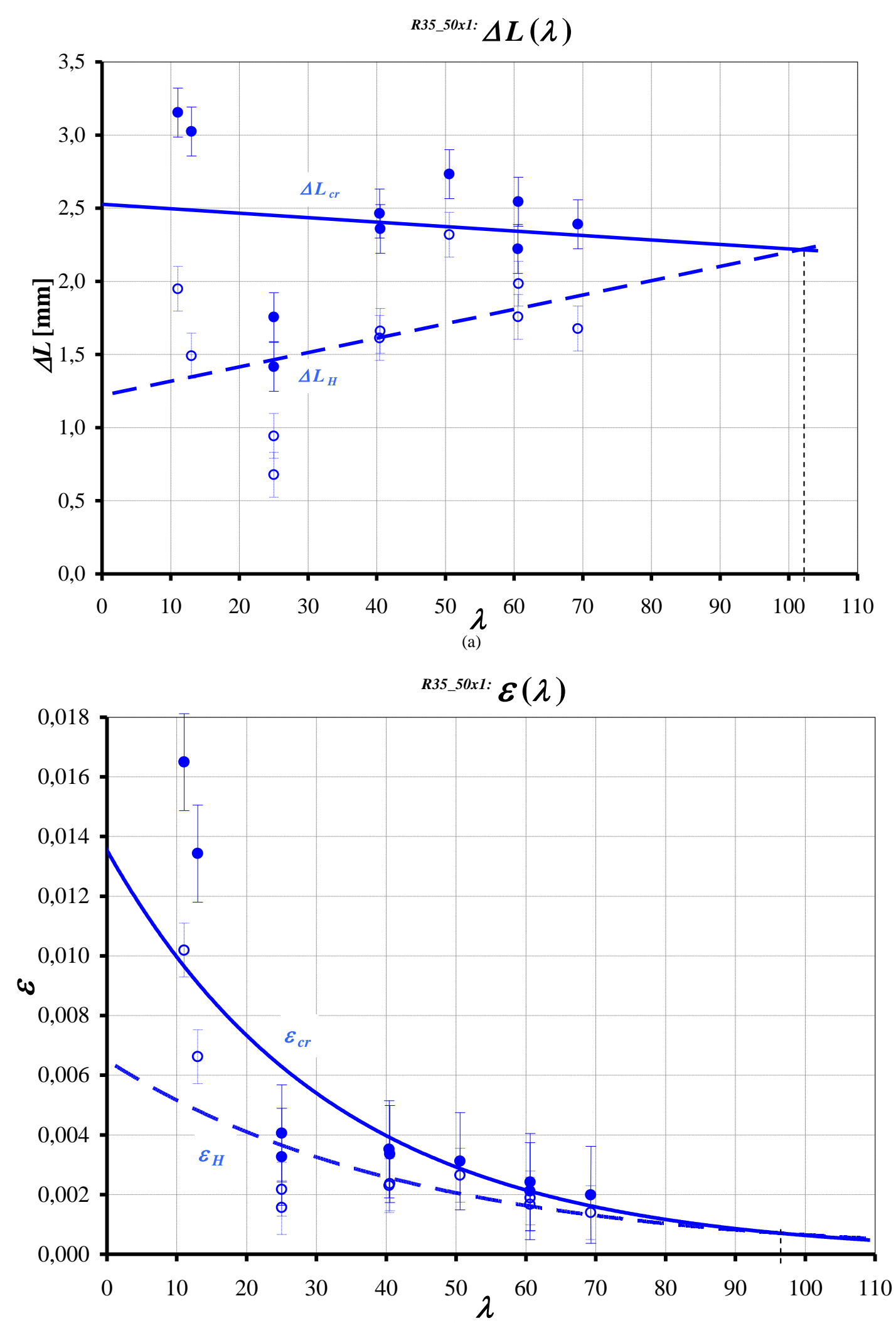

(b)

Fig. 23: Approximated functions: (a) $\Delta L(\lambda)$ and (b) $\varepsilon(\lambda)$ of the specimens with cross-section $\phi 50 \times 1$ made of steel R35, compressed through ball-and-socket joints with friction 
Krzysztof Murawski / International Journal of Structural Glass and Advanced Materials Research 2021, Volume 5: 82.114

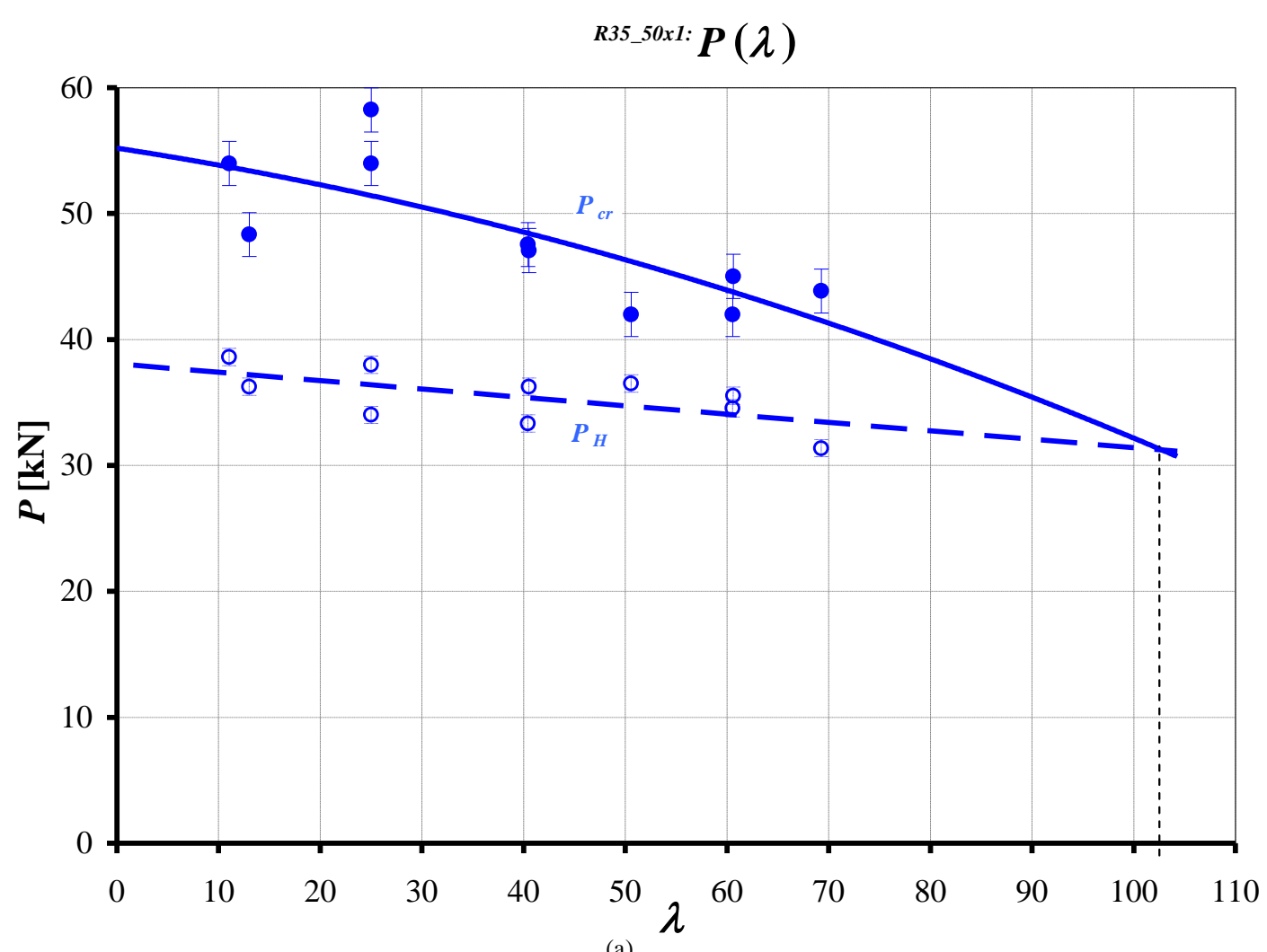

(a)

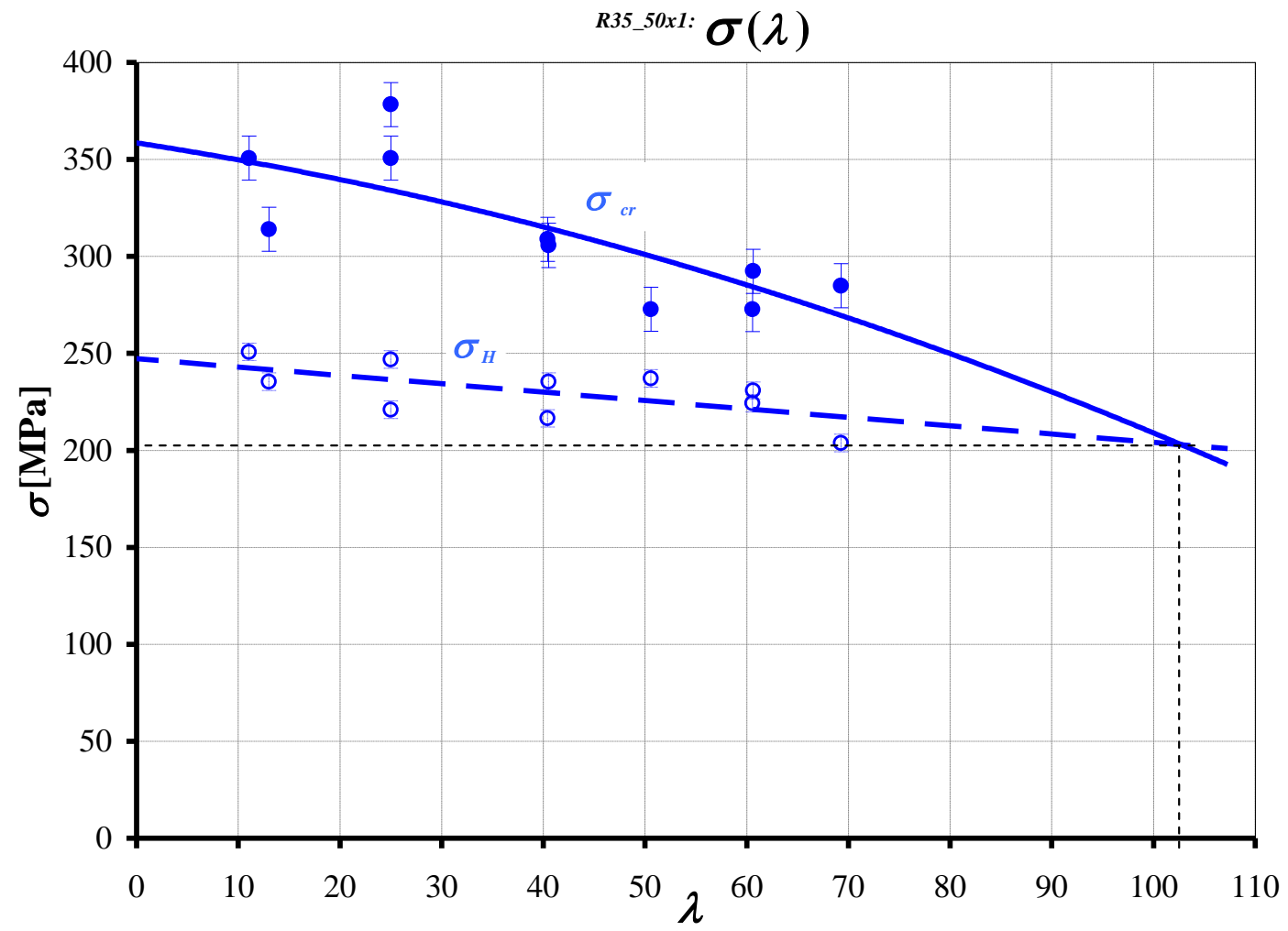

(b)

Fig. 24: Approximated functions: (a) $P(\lambda)$ and (b) $\sigma(\lambda)$ of the specimens with cross-section $\phi 50 \times 1$ made of steel R35, compressed through ball-and-socket joints with friction 
Krzysztof Murawski / International Journal of Structural Glass and Advanced Materials Research 2021, Volume 5: 82.114 DOI: 10.3844/sgamrsp.2021.82.114

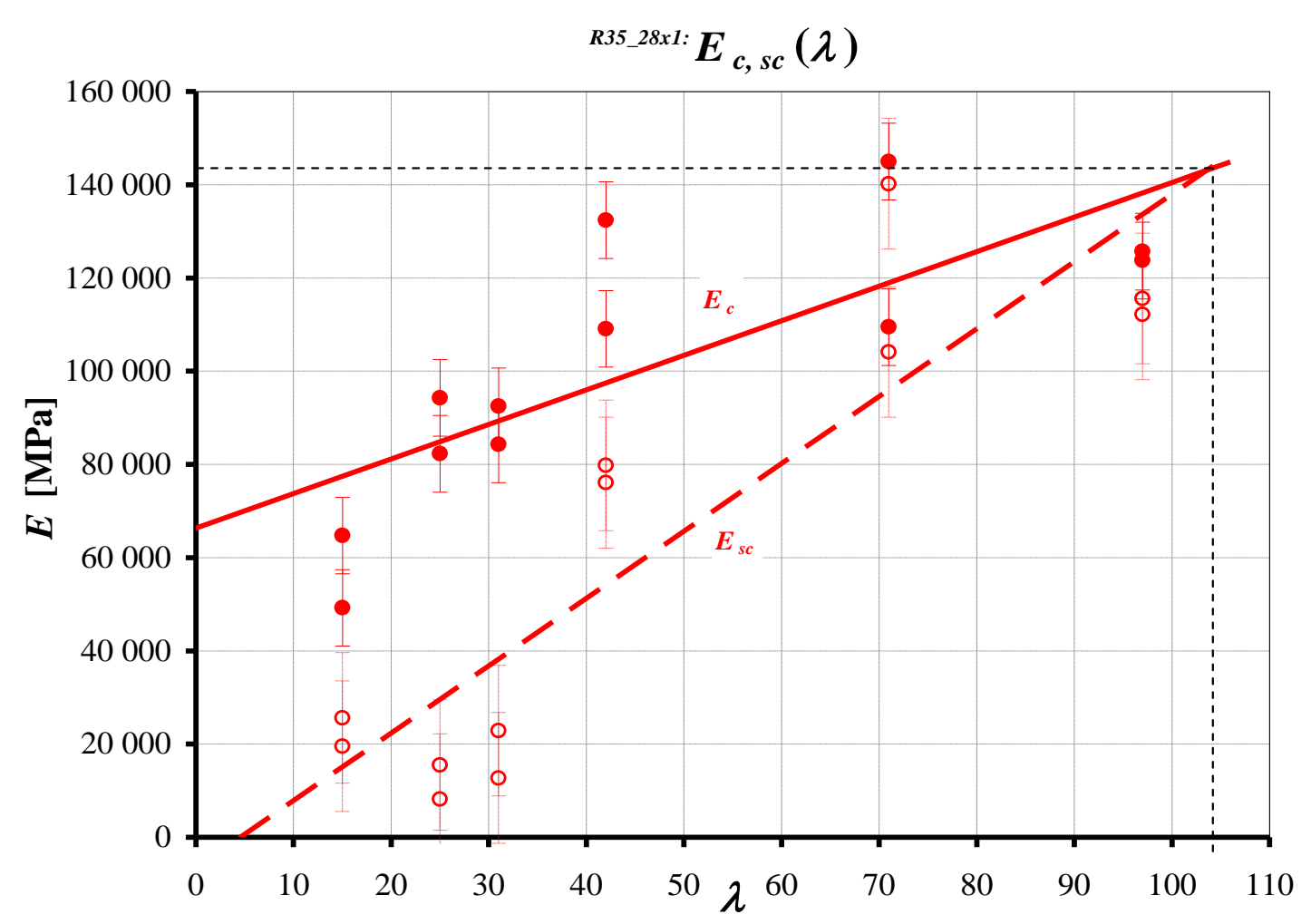

(a)

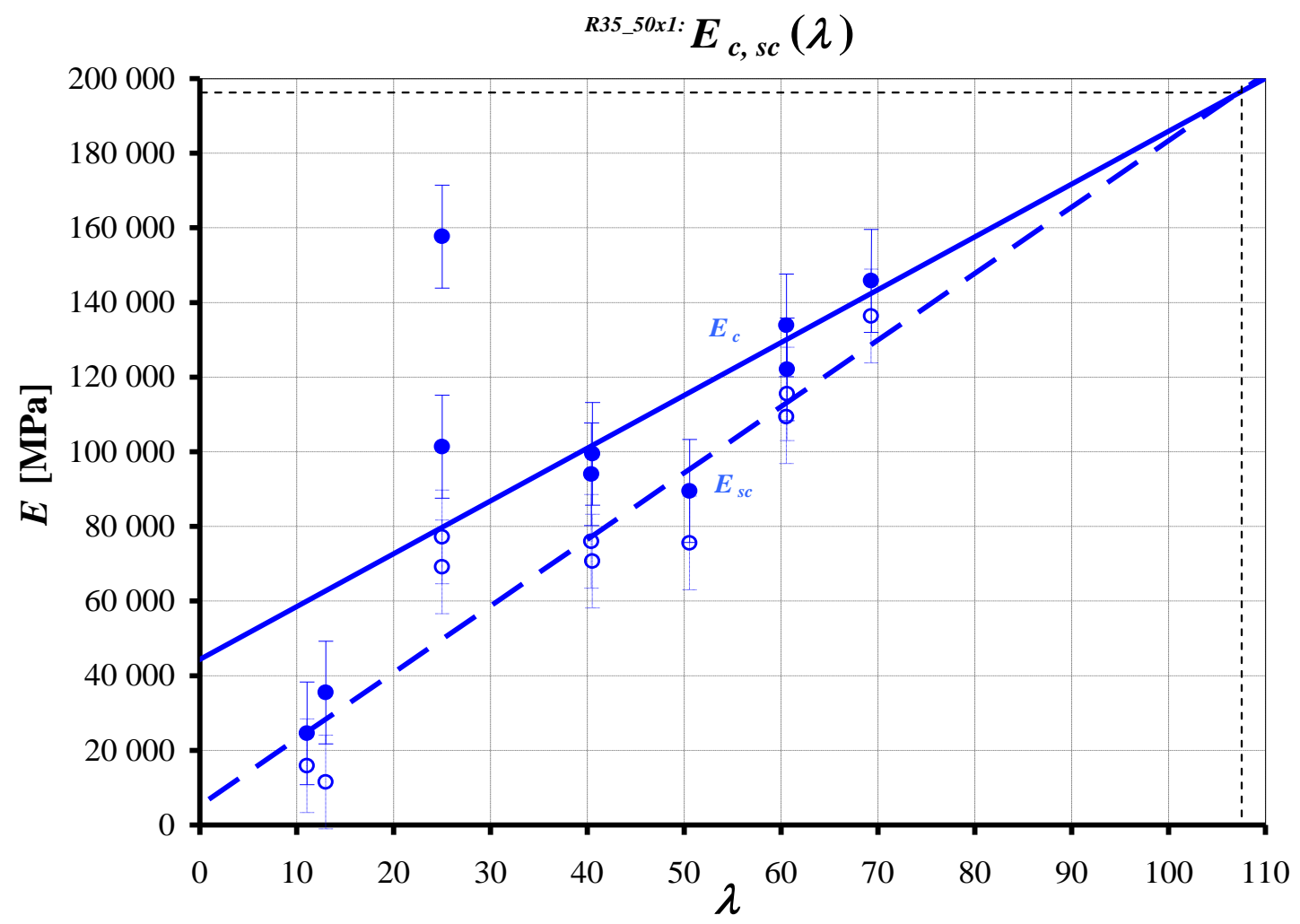

(b)

Fig. 25: Approximated functions $E_{c}(\lambda)$ and $E_{s c}(\lambda)$ of the specimens with cross-section (a) $\phi 26 \times 1$ and (b) $\phi 50 \times 1$ made of steel R35, compressed through ball-and-socket joints with friction 
Krzysztof Murawski / International Journal of Structural Glass and Advanced Materials Research 2021, Volume 5: 82.114 DOI: 10.3844/sgamrsp.2021.82.114

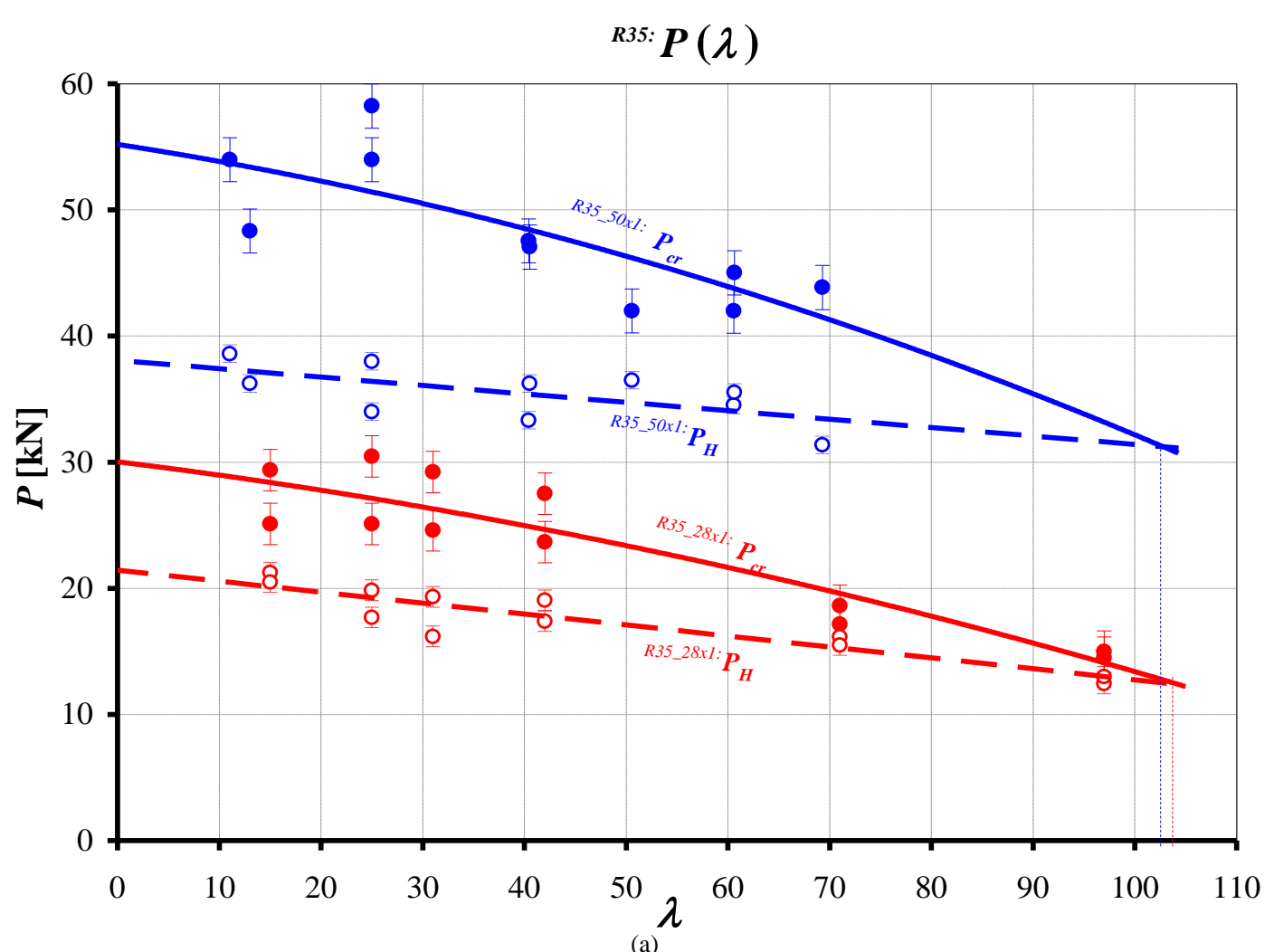

(a)

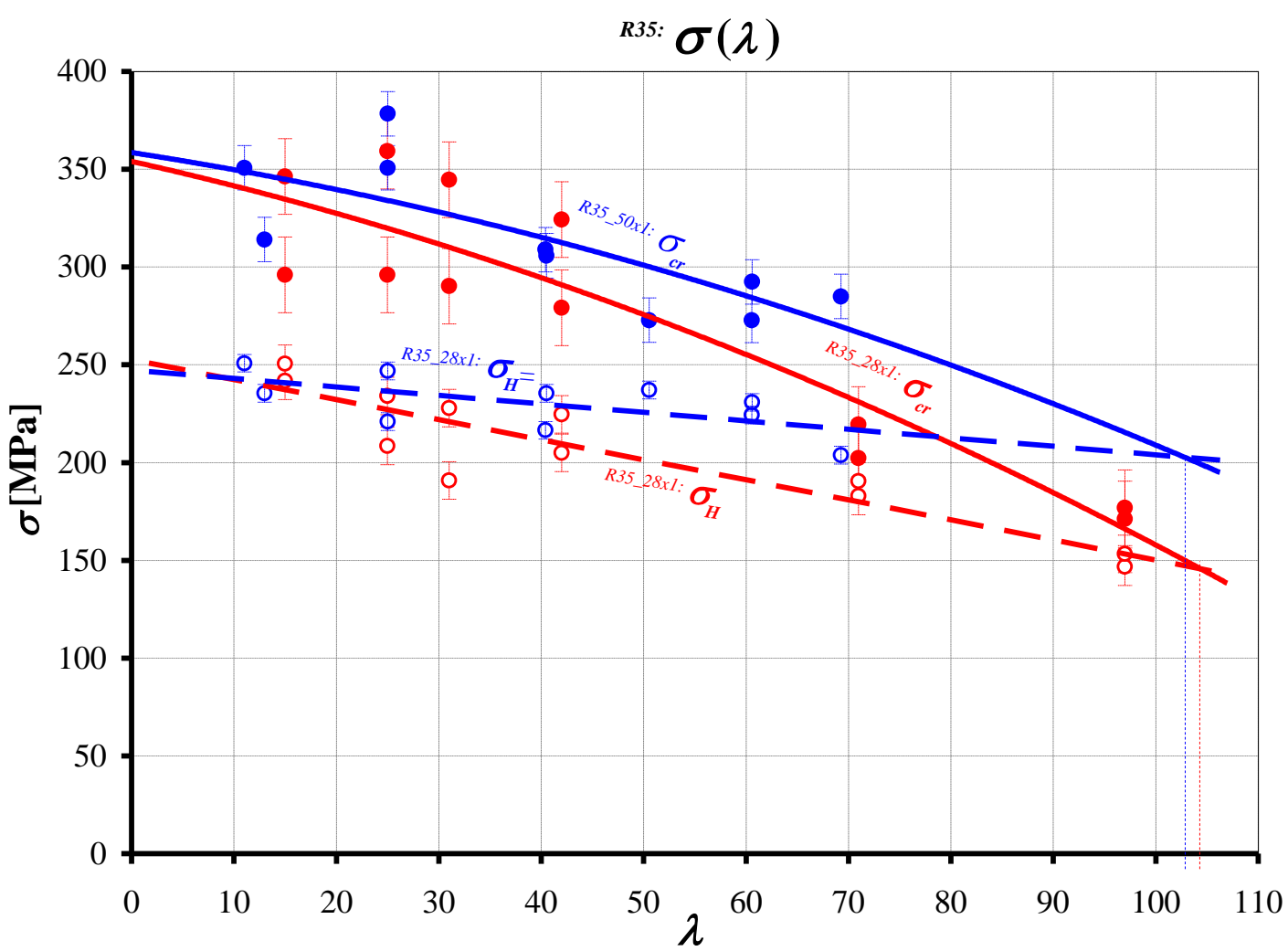

(b)

Fig. 26: Sets of the approximated functions: (a) $P(\lambda)$ and (b) $\sigma(\lambda)$ of the specimens made of steel R35, compressed through ball-andsocket joints with friction 


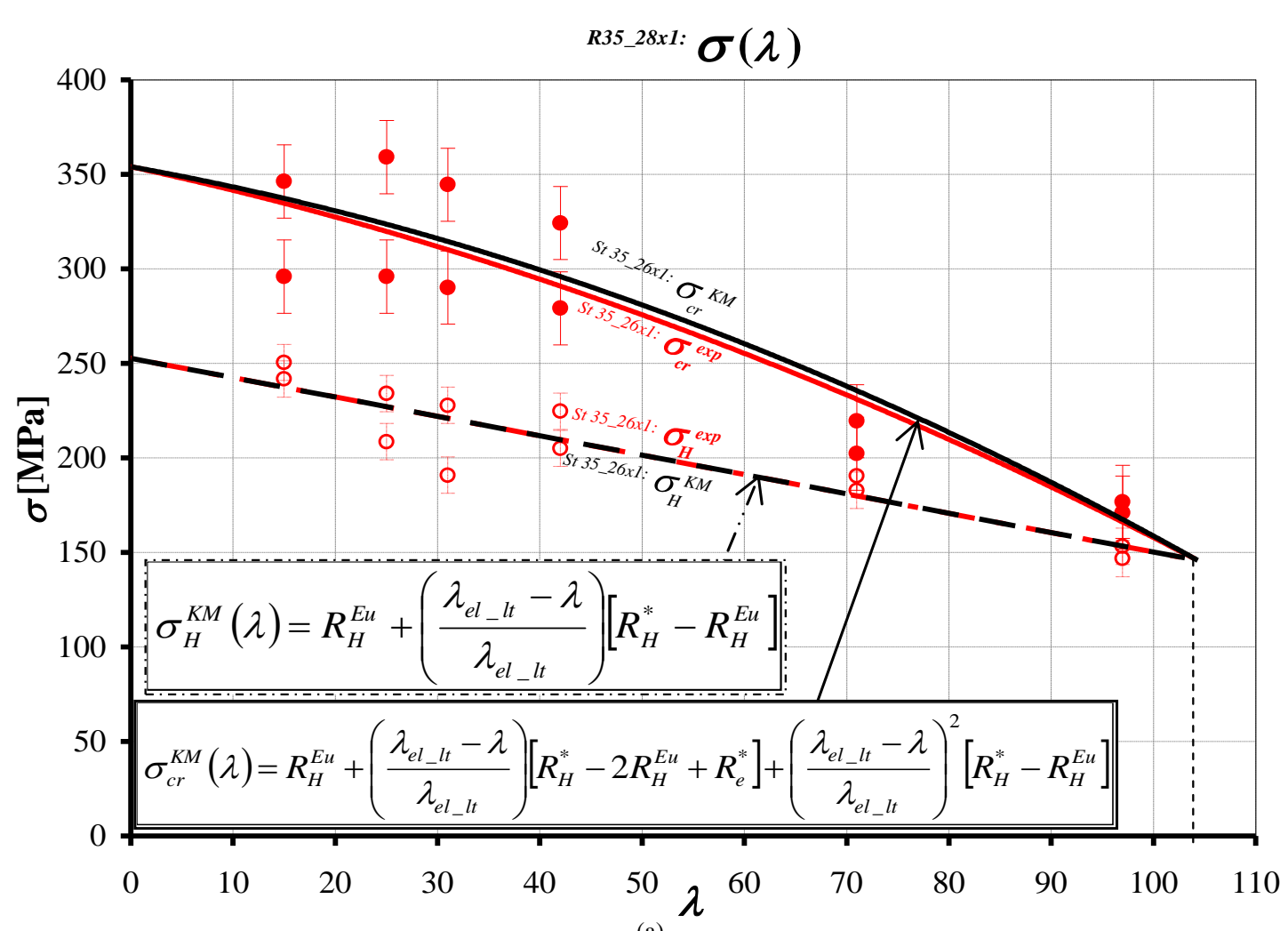

(a)

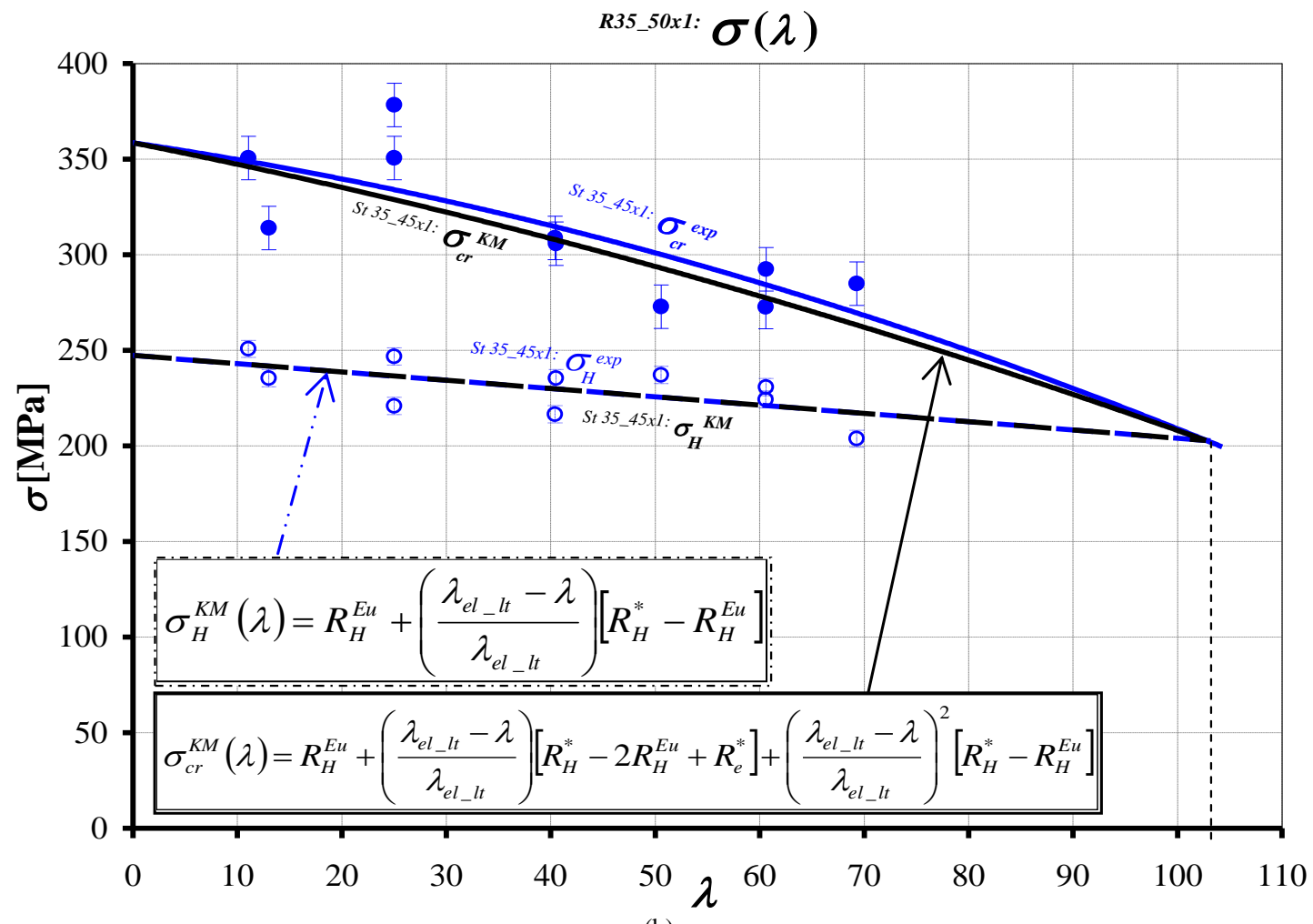

(b)

Fig. 27: Sets of the functions: approximated experimental $\sigma^{\exp }(\lambda)$ and theoretical $\sigma^{K M}(\lambda)$ of the specimens made of steel R35: (a) $\phi 28 \times 1$ and (b) $\phi 50 \times 1$, compressed through ball-and-socket joints with friction 


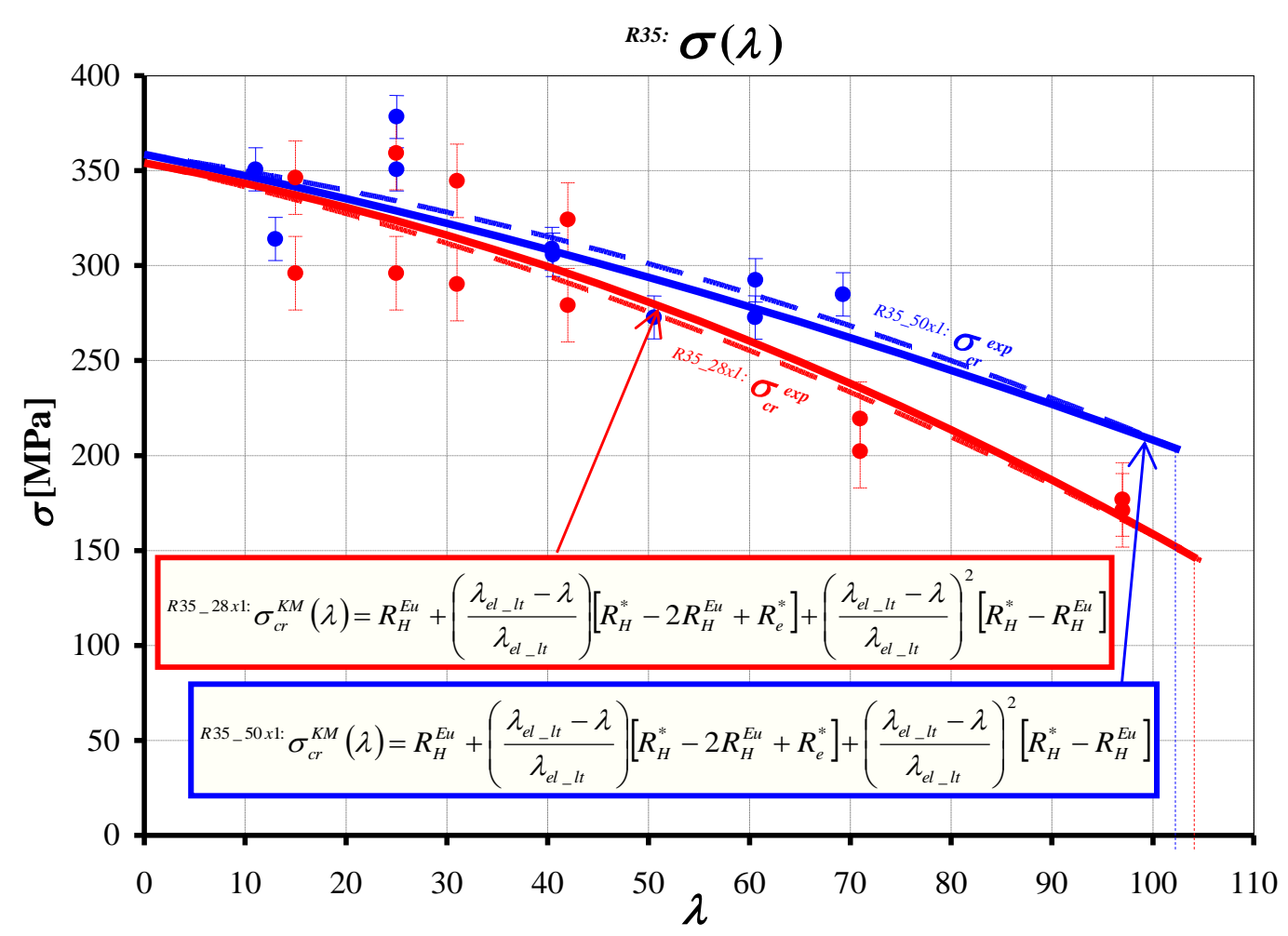

Fig. 28: Functions $\sigma_{c r}(\lambda)$ according to the modified Engesser-Kármán -Shanley’s hypothesis and approximated curves obtained from experiments for columns $\phi 50 \times 1$ and $\phi 28 \times 1$ made of steel R35

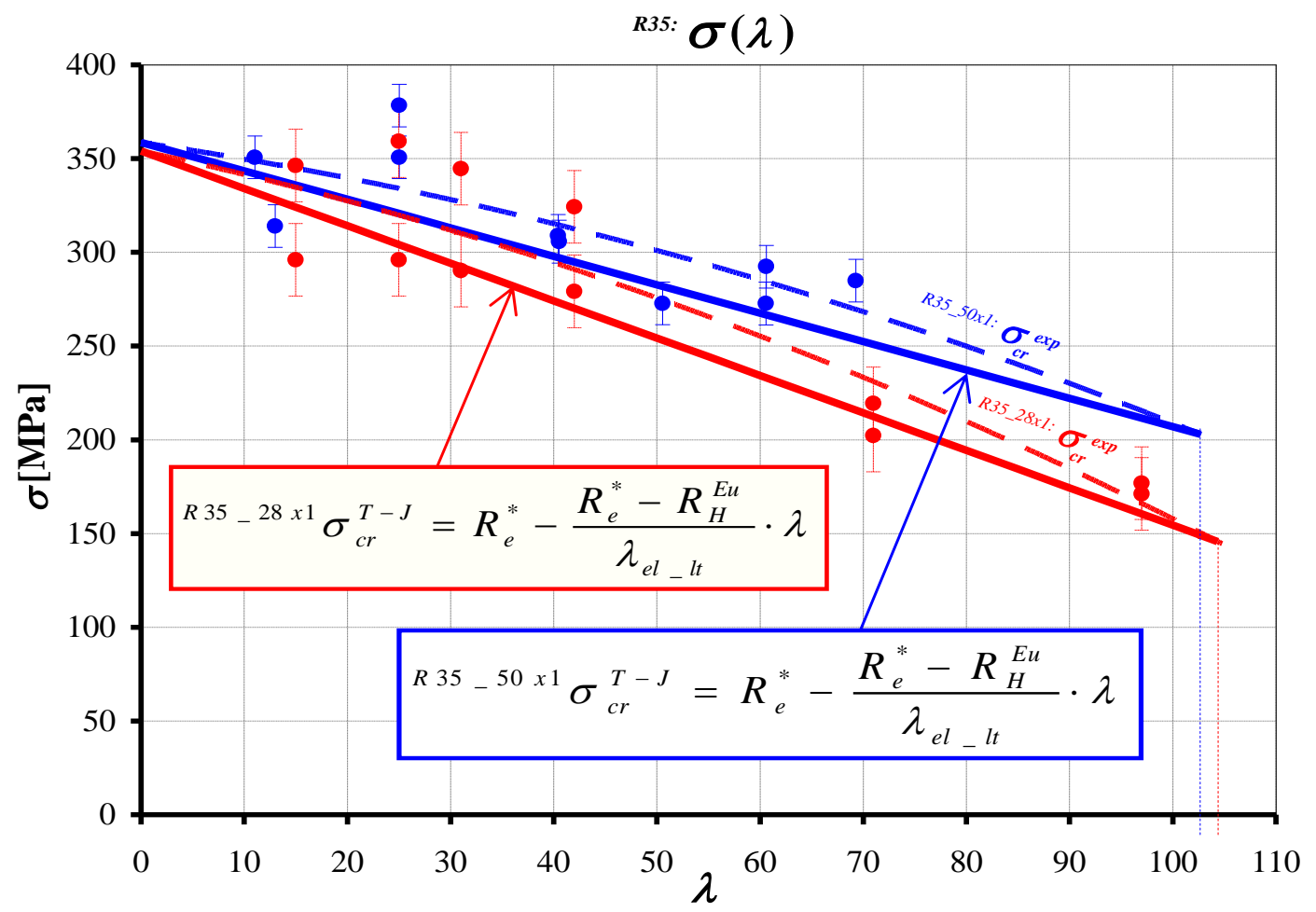

Fig. 29: Functions $\sigma_{c r}(\lambda)$ according to the (Tetmajer, 1886; Jasiński, 1894) simplification and approximated curves obtained from experiments for columns $\phi 50 \times 1$ and $\phi 28 \times 1$ made of steel R35 


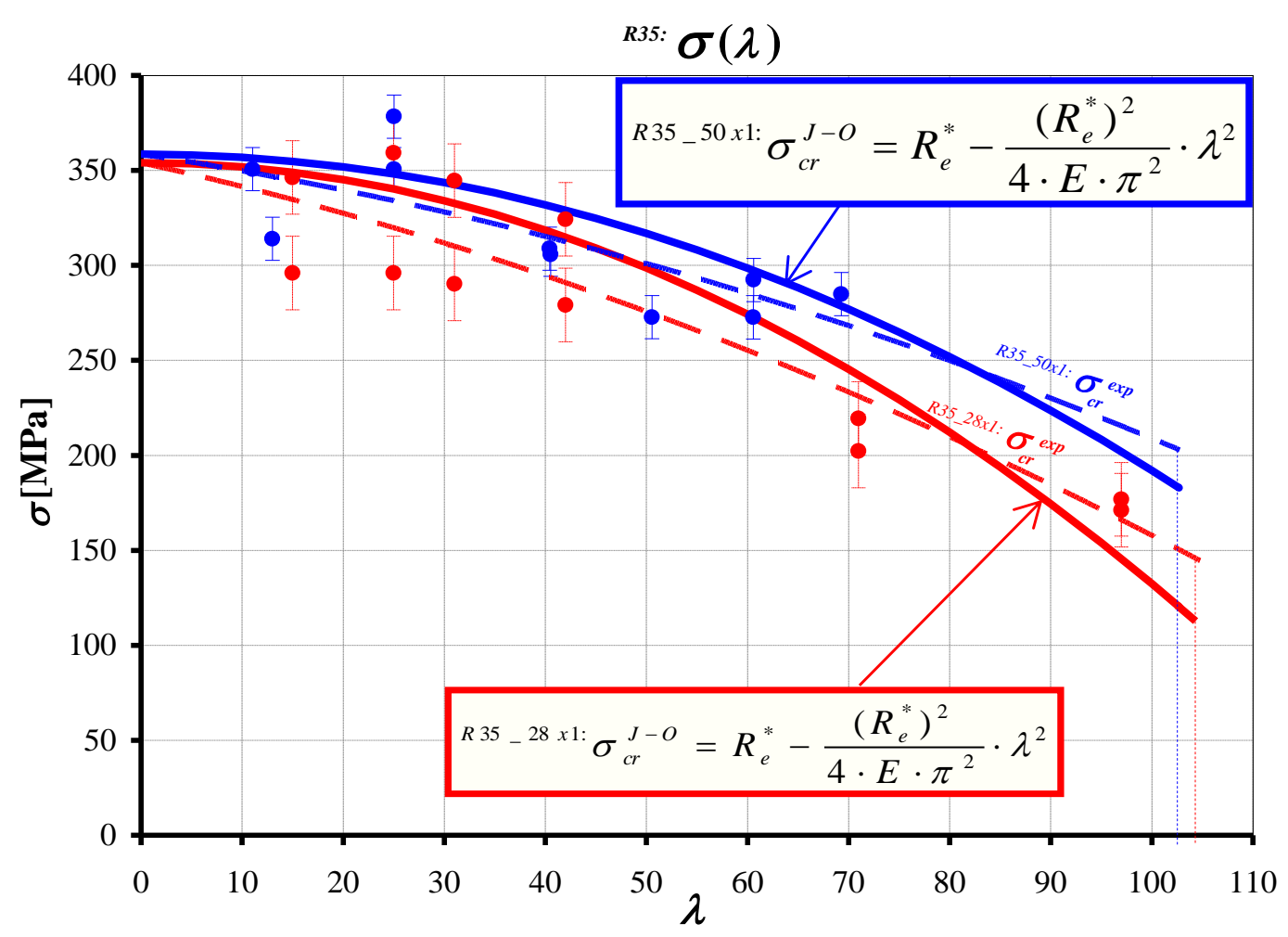

Fig. 30: Functions $\sigma_{c r}(\lambda)$ according to Johnson-Ostenfeld's (1898) simplification and approximated curves obtained from experiments for columns $\phi 50 \times 1$ and $\phi 28 \times 1$ made of steel R35

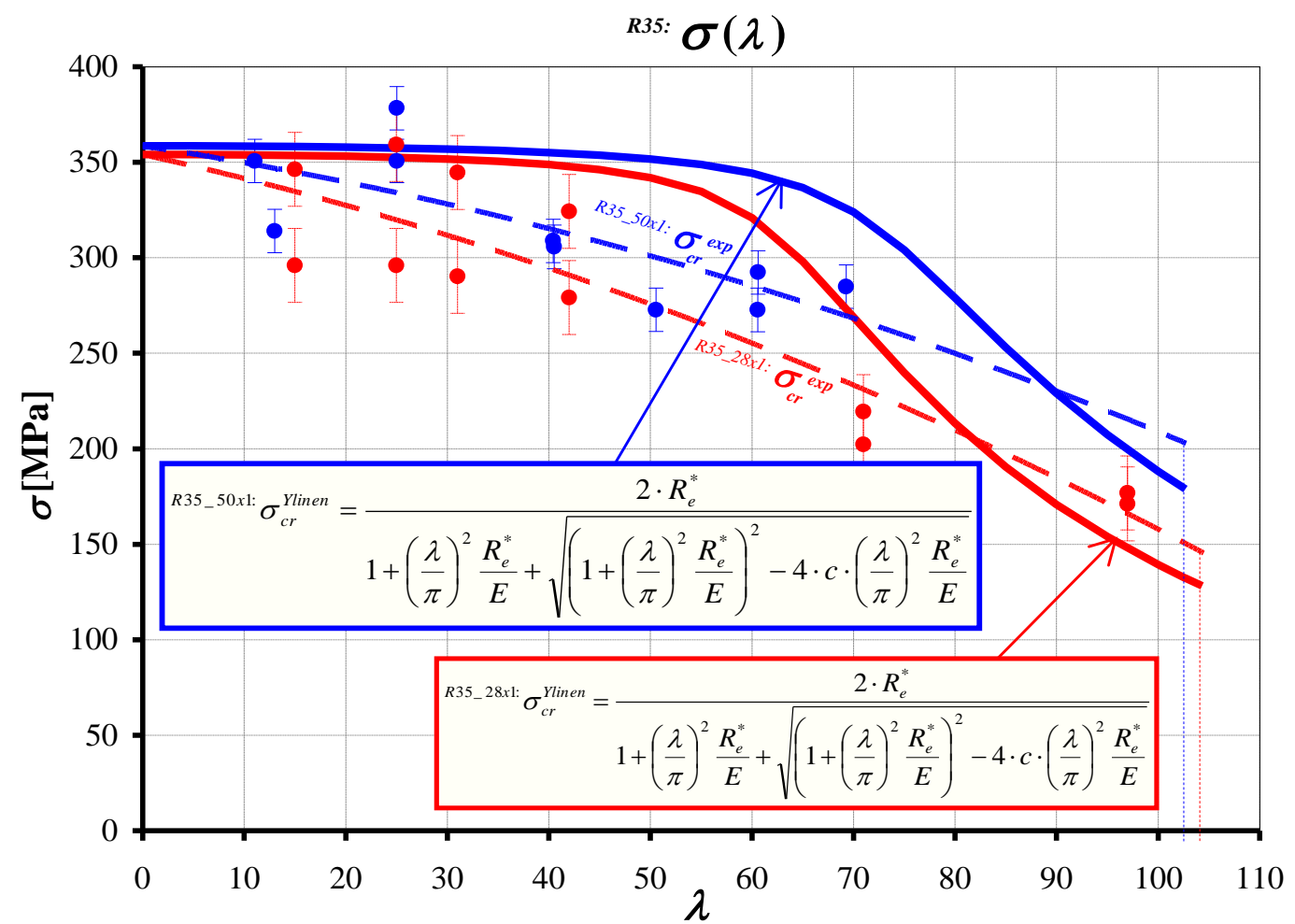

Fig. 31: Functions $\sigma_{c r}(\lambda)$ according to Ylinen's hypothesis (1956) and approximated curves obtained from experiments for columns $\phi 50 \times 1$ and $\phi 28 \times 1$ made of steel R35 


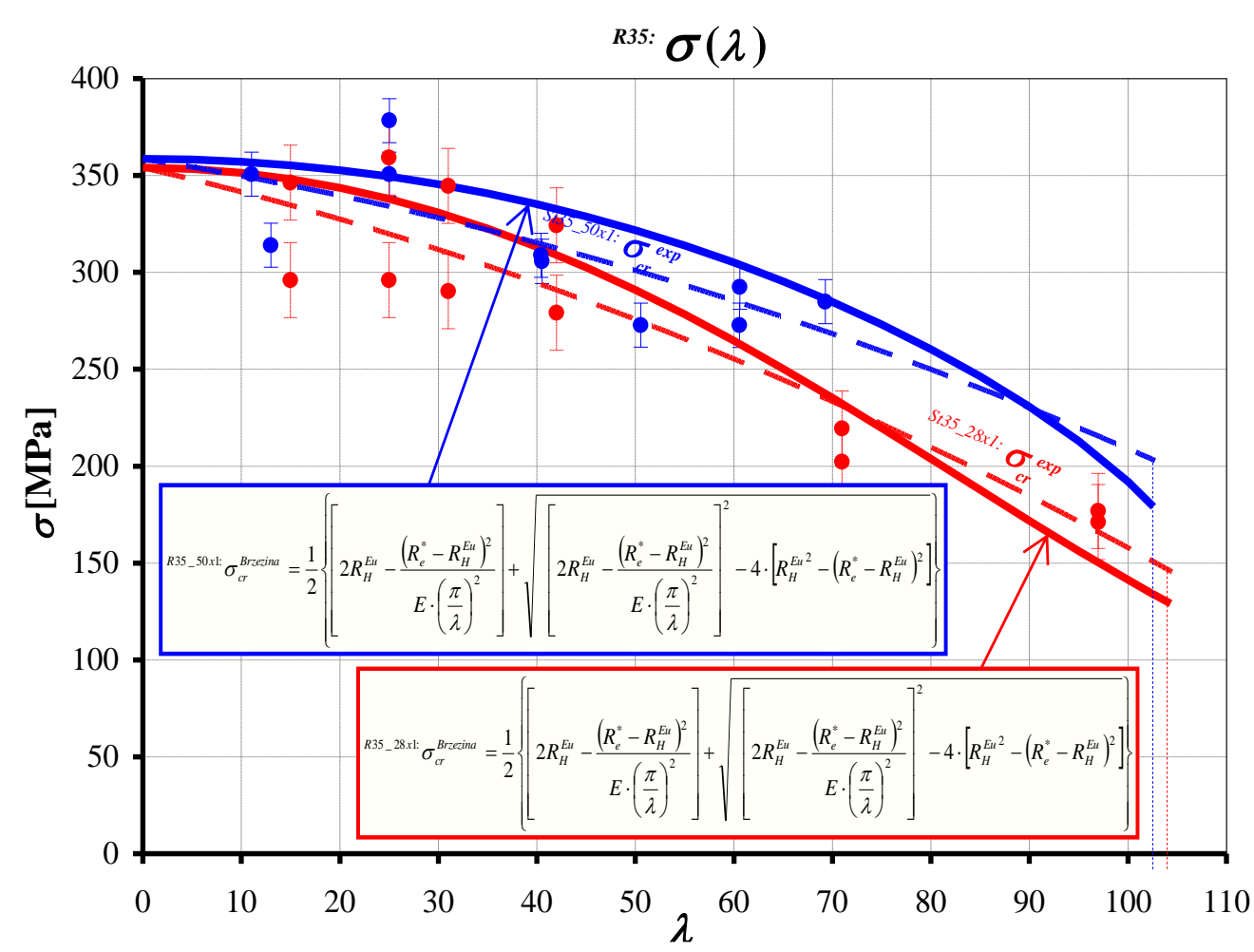

Fig. 32: Functions $\sigma_{c r}(\lambda)$ according to the Březina's hypothesis (1966) and approximated curves obtained from experiments for columns $\phi 50 \times 1$ and $\phi 28 \times 1$ made of steel R35

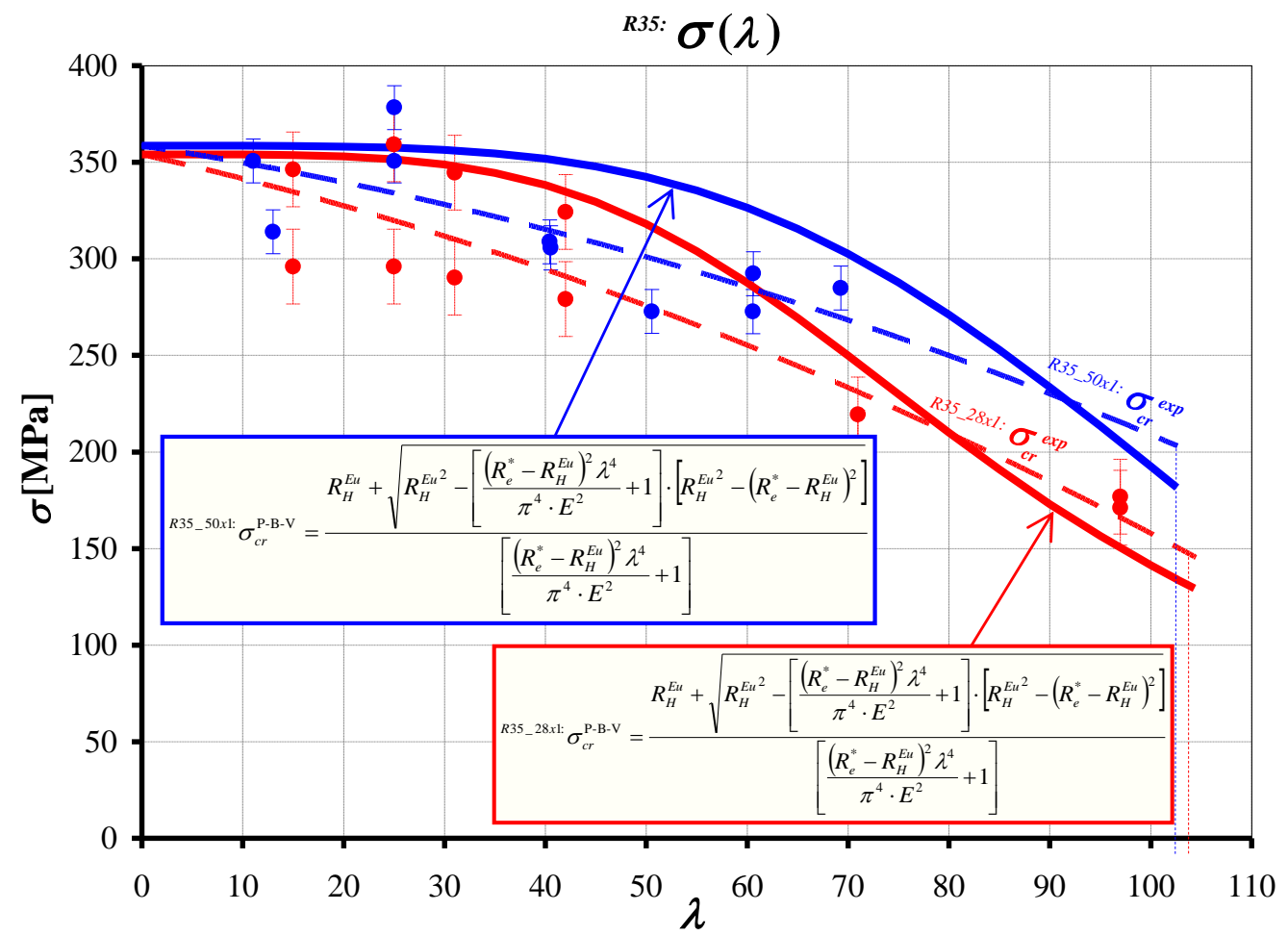

Fig. 33: Functions $\sigma_{c r}(\lambda)$ according to the (Pearson, 1950; Bleich, 1952; Vol'mir's, 1965) hypothesis and approximated curves from experiments for columns $\phi 50 \times 1$ and $\phi 28 \times 1$ made of steel R35 
Table 1: Maximal differences $\Delta[\%]$ between results obtained according to the author's approximated hypothesis and results obtained from of the tests on the columns $\phi 50 \times 1$ made of steel R35

$R 35 \_50 x 1: \Delta_{c r_{-} \max }^{\exp -K M}[\mathrm{MPa}]=\left(\sigma_{c r}^{\mathrm{exp}}-\sigma_{c r}^{K M}\right)_{\max }$

7,06

${ }^{R 35}{ }_{-} 50 x \mathrm{x}: \Delta_{c r_{-} \max }^{\exp -(T-J)}[\mathrm{MPa}]=\left(\sigma_{c r}^{\exp }-\sigma_{c r}^{T-J}\right)_{\max }$

18,17

${ }^{R 35-50 x 1:} \Delta_{c r_{-} \max }^{\exp (J-O)}[\mathrm{MPa}]=\left(\sigma_{c r}^{\exp }-\sigma_{c r}^{J-O}\right)_{\max }$

$-16,70$

${ }^{R 35} \_50 x 1 \mathrm{~s} \Delta_{c r_{-} \max }^{\exp }[\mathrm{MPa}]=\left(\sigma_{c r}^{\mathrm{exp}}-\sigma_{c r}^{\text {Ylinen }}\right)_{\max }$

$-59,90$

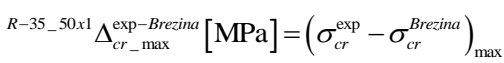

24,33

${ }^{R 35}{ }^{50 x 1} \Delta_{c r_{-} \max }^{\text {exp- }-\mathrm{P}-\mathrm{V})}[\mathrm{MPa}]=\left(\sigma_{c r}^{\text {exp }}-\sigma_{c r}^{\mathrm{P}-\mathrm{B}-\mathrm{V}}\right)_{\max }$

$-42,06$

$$
{ }^{R 35 \_50 x 1:} \Delta_{c r_{-} \max }^{\exp / K M}[\%]=\left(\frac{\sigma_{c r}^{\exp }-\sigma_{c r}^{K M}}{\sigma_{c r}^{\exp }}\right)_{\max } \cdot 100 \%
$$

$$
{ }^{R 35 \_50 x 1:} \Delta_{c r_{-} \max }^{\exp (T-J)}[\%]=\left(\frac{\sigma_{c r}^{\exp }-\sigma_{c r}^{T-J}}{\sigma_{c r}^{\exp }}\right)_{\max } \cdot 100 \%
$$

6,19

${ }^{R 35 \_50 x 1:} \Delta_{c r_{-} \max }^{\exp (J)}[\%]=\left(\frac{\sigma_{c r}^{\exp }-\sigma_{c r}^{J-O}}{\sigma_{c r}^{\exp }}\right)_{\max } \cdot 100 \%$

$-5,38$

${ }^{R 35}{ }^{50 x 1} \Delta_{c r_{-} \max }^{\text {exp } / \text { linen }}[\%]=\left(\frac{\sigma_{c r}^{\text {exp }}-\sigma_{c r}^{\text {Ylinen }}}{\sigma_{c r}^{\exp }}\right)_{\max } \cdot 100 \%$

$-21,63$

${ }^{R-35_{-} 50 x \mathrm{xl}} \Delta_{c r_{-} \max }^{\text {exp } / \text { rezina }}[\%]=\left(\frac{\sigma_{c r}^{\text {exp }}-\sigma_{c r}^{\text {Brezina }}}{\sigma_{c r}^{\exp }}\right)_{\max } \cdot 100 \%$

11,99

${ }^{R 35}-50 x 1: \Delta_{c r_{-} \max }^{\text {exp } / \mathrm{PB})}[\%]=\left(\frac{\sigma_{c r}^{\mathrm{exp}}-\sigma_{c r}^{\mathrm{P}-\mathrm{B}-\mathrm{V}}}{\sigma_{c r}^{\mathrm{exp}}}\right)_{\max } \cdot 100 \%$

$-14,42$

Table 2: Maximal differences $\Delta[\%]$ between results obtained according to the author's approximated hypothesis and results obtained from of the tests on the columns $\phi 28 \times 1$ made of steel R35

${ }^{R 35 \_28 x 1:} \Delta_{c r_{-} \max }^{\exp -K M}[\mathrm{MPa}]=\left(\sigma_{c r}^{\exp }-\sigma_{c r}^{K M}\right)_{\max }$

$-5,21$

${ }^{R 35-28 x 1:} \Delta_{c r_{-} \max }^{\exp (T-J)}[\mathrm{MPa}]=\left(\sigma_{c r}^{\exp }-\sigma_{c r}^{T-J}\right)_{\max }$

21,46

${ }^{R 35}{ }^{28 x 1:} \Delta_{c r_{-} \max }^{\exp (J-O)}[\mathrm{MPa}]=\left(\sigma_{c r}^{\exp }-\sigma_{c r}^{J-O}\right)_{\max }$

33,06

${ }^{R 35-28 x 1:} \Delta_{c r_{-} \max }^{\exp }[\mathrm{MPa}]=\left(\sigma_{c r}^{\exp }-\sigma_{c r}^{\text {Ylinen }}\right)_{\max }$

$-68,93$

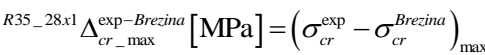

16,82

${ }^{R 35}-28 \times 1 \Delta_{c r_{-} \max }^{\text {exp- }-\mathrm{P})}[\mathrm{MPa}]=\left(\sigma_{c r}^{\text {exp }}-\sigma_{c r}^{\mathrm{P}-\mathrm{B}-\mathrm{V}}\right)_{\max }$

$-44,09$

For the columns $\phi 28 \times 1$ on the base of the tests were assumed: $E^{*}=143230 \mathrm{MPa}, \lambda_{\text {el-lt }}=104.331, R_{e}{ }^{*}=$ 354.05 MPa, $R_{H}{ }^{*}=252,68 \mathrm{MPa}, R_{H}{ }^{E u}=145.803 \mathrm{MPa}$.
${ }^{R 35 \_28 x 1:} \Delta_{c r_{-} \max }^{\exp / K M}[\%]=\left(\frac{\sigma_{c r}^{\exp }-\sigma_{c r}^{K M}}{\sigma_{c r}^{\exp }}\right)_{\max } \cdot 100 \%$

$-2,01$

${ }^{R 35 \_28 x 1:} \Delta_{c r}^{\exp /(T-J)}[\%]=\left(\frac{\sigma_{c r}^{\exp }-\sigma_{c r}^{T-J}}{\sigma_{c r}^{\exp }}\right)_{\max } \cdot 100 \%$

8,26

${ }^{R 35 \_28 x 1:} \Delta_{c r_{-} \max }^{\exp /(J-O)}[\%]=\left(\frac{\sigma_{c r}^{\exp }-\sigma_{c r}^{J-O}}{\sigma_{c r}^{\exp }}\right)_{\max } \cdot 100 \%$

22,67

${ }^{R 35}{ }_{-28 x 1} \Delta_{c r_{-} \max }^{\exp / \text { linen }}[\%]=\left(\frac{\sigma_{c r}^{\exp }-\sigma_{c r}^{\text {Ylinen }}}{\sigma_{c r}^{\exp }}\right)_{\max } \cdot 100 \%$

$-25,94$

$R 35_{-28 x 1:} \Delta_{c r_{-} \max }^{\text {exp/Brina }}[\%]=\left(\frac{\sigma_{c r}^{\text {exp }}-\sigma_{c r}^{\text {Brezina }}}{\sigma_{c r}^{\text {exp }}}\right)_{\max } \cdot 100 \%$

11,51

${ }^{R 35_{-} 28 x \mathrm{xl}:} \Delta_{c r_{-} \max }^{\mathrm{exp} / \mathrm{P}-\mathrm{V})}[\%]=\left(\frac{\sigma_{c r}^{\mathrm{exp}}-\sigma_{c r}^{\mathrm{P}-\mathrm{B}-\mathrm{V}}}{\sigma_{c r}^{\mathrm{exp}}}\right) \cdot 100 \%$

$-15,45$
The average values were assumed: $E^{*}=166614$ $\mathrm{MPa}, \lambda_{\text {el-lt }}=102.6, R_{e}{ }^{*}=346.54 \mathrm{MPa}, R_{H}{ }^{*}=268.24 \mathrm{MPa}$, $R_{H}^{E u}=156.0 \mathrm{MPa}$. 
The tests were executed by ball-and-sockets joints what caused increasing partition of friction between balls and sockets with increasing load.

\section{Conclusion}

For Johnson-Ostenfeld's, Ylinen's, Březina's and Pearson-Bleich-Vol'mir's theories the surface functions are almost flat in the most part-the bronze parts of the surface functions in Figs. 3 to 10.

The formulas given by those theories don't allow presenting them depending on the transverse crosssection area $A$ and slenderness ratio $\lambda$ together - for what allows the technical stability theory for columns in elastic-plastic states. That proves that those theories are simplified and limited.

They don't allow presenting the functions for the shell stresses and strains-for what allows the technical stability theory for columns in elastic-plastic states.

Besides, it was concluded that:

- $\quad$ For increasing value of a slenderness ratio $\lambda$ the values of the compress modulus $E_{c}$ and secant compress modulus $E_{s c}$ were also increasing: $E_{c}\left(\lambda_{i}\right)<E_{c}\left(\lambda_{i+1}\right)<$ $E_{c}\left(\lambda_{i+2}\right)$ and $E_{s c}\left(\lambda_{i}\right)<E_{s c}\left(\lambda_{i+1}\right)<E_{s c}\left(\lambda_{i+2}\right)$ - Fig. 1 to 25

- $\quad$ For the slenderness ratio limiting elastic states $\lambda_{\text {el-lt }}$ the compress modulus $E_{c}$ and secant compress modulus $E_{s c}$ were equal and that value was signed as $E^{*}=E_{c}\left(\lambda_{e l-l t}\right)=E_{s c}\left(\lambda_{e l-l t}\right) \approx E$ - Figs. 1 to 25

- With increasing of the transverse cross-section area $A$ the shortness $\Delta L_{H}(\lambda)$ is increasing too, but $\Delta L_{c r}(\lambda)$ is decreasing and they meet together at $\lambda_{\text {el-lt }}-$ Fig. $21 \mathrm{a}$ and $23 \mathrm{a}$

- The strains $\varepsilon(\lambda)$ are decreasing exponentially-Fig. $21 \mathrm{~b}$ and $23 \mathrm{~b}$

- With increasing of the transverse cross-section area $A$ the forces $P_{c r}{ }^{*}$ and $P_{H}{ }^{*}$ are increasing too, but the stresses $R_{e}{ }^{*}$ and $R_{H}{ }^{*}$ are almost constant-Fig. 26

- With increasing of the transverse cross-section area $A$ the stresses $\sigma_{c r}(\lambda)$ and $R_{H}(\lambda)$ are increasing too and the stress $R_{H}^{E u}$ is also increasing-Fig. 26. The stress $R_{H}(\lambda)$ is changing because its values were measured from the curves $\sigma(\varepsilon)$ obtained from the experiments and they consisted the change of an elastic part in the critical transverse cross-sections $A$ with the changing slenderness ratio

- With increasing of transverse cross-section area $A$ the slenderness ratios limiting the elastic states $\lambda_{\text {el_lt }}$ are almost the same-Fig. 26

It was also concluded that the approximated theory of technical stability for columns in the elastic-plastic states gives the possibility to determine the stress $R_{H}(\lambda)$ as well as $\sigma_{c r}(\lambda)$.

\section{Ethics}

The content of this study is the changed preprint (Murawski, 2020b) according to the issuer requirements and reviewers' and own author's corrections.

\section{References}

Abbas, R., \& Awazli, A. (2017). Behavior of Reinforced Concrete Columns Subjected to Axial Load and Cyclic Lateral Load. University of Baghdad Engineering Journal, 23, 21-40. https://joe.uobaghdad.edu.iq/index.php/main/article/ view/69

Abdel-Karim, M., Abdel-Rahman, G., Said, M., \& Shaaban, I. (2017). Proposed Model for Strength Analysis of HSC Eccentrically Loaded Slender Columns. Magazine of Concrete Research, 70. https://doi.org/10.1680/jmacr.17.00137

Abdel-Lateef, T. H., Dabaon, M. A., Abdel-Moez, O. M., \& Salama, M. I. (2001, April). Buckling loads of columns with gradually changing cross-section subjected to combined axial loading. In Fourth Alexandria International Conference on Structural and Geotechnical Engineering (pp. 2-4).

Abdulazeez, M., ElGawady, M., \& Abdelkarim, O. (2018). Bending and Buckling Behavior of HollowCore FRP-Concrete-Steel Columns. Journal of Bridge Engineering, 24. https://doi.org/10.1061/(ASCE)BE.19435592.0001419

Abed, F., AlHamaydeh, M., \& Barakat, S. (2013). Nonlinear Finite-Element Analysis of Buckling Capacity of Pretwisted Steel Bars. Journal of Engineering Mechanics, ASCE, 139, 791-801. https://doi.org/10.1061/(ASCE)EM.19437889.0000528

Abedini, M., Mutalib, A., Zhang, C., Mehrmashhadi, J., Raman, S. N., Alipour, R., Momeni, T., \& Mussa, M. (2020). Large deflection behavior effect in reinforced concrete columns exposed to extreme dynamic loads. Frontiers of Structural and Civil Engineering, 14. https://doi.org/10.1007/s11709. 020-0604-9

Ahiwale, D., Khartode, R., Bhapkar, A., Narule, G., \& Sharma, K. (2020). Influence of compressive load on concrete filled steel tubular column with variable thickness. Innovative Infrastructure Solutions, $6, \quad 1-14$. https://doi.org/10.1007/s41062-020-00390-z

Al-Kamal, M. (2016). Design for Prestressed Concrete Flexural Members against Progressive Collapse. Thesis for PhD. https://www.researchgate.net/publication/32084011 3_Design_For_Prestressed_Concrete_Flexural_Me mbers_Against_Progressive_Collapse 
Alomarah, A., Masood, S., \& Ruan, D. (2020). Outof-plane and in-plane compression of additively manufactured auxetic structures. Aerospace Science and Technology, 106, 106107. https://doi.org/10.1016/j.ast.2020.106107

Alvarenga, A. R., \& Silveira R. A. (2006). Considerations on advanced analysis of steel portal frames. In Proceedings of ECCM III European Conference on Computational Mechanics-Solids, Structures and Coupled Problems in Engineering (p.2119). https://doi.org/10.1007/1-4020-5370-3_103

Ammash, H. (2017). Shape optimization of innovation cold-formed steel columns under uniaxial compressive loading. Jordan Journal of Civil Engineering, $\quad 11, \quad 473-489$. https://search.proquest.com/openview/1c4bf82daa05 41434070c902473cba42/1?pqorigsite $=$ gscholar $\& \mathrm{cbl}=2035891$

Ananthi, G. B., \& Anbarasu, M. (2014). A Study on Cold-formed Steel Lipped Built up Channel Sections Subjected to Axial Compression. Structural Engineering Convention, New Delhi.

Ananthi, G. B., Roy, K., \& Lim, J. B. P. (2021). Nonlinear behaviour and design of web stiffened battened built-up stainless steel channel sections under axial compression. Structures, 30. https://doi.org/10.1016/j.istruc.2021.01.014

Andreev, V. I., \& Tsybin, N. Y. (2015). On the Stability of Rod with Variable Cross-section. Procedia Engineering. $111 . \quad 42-48$. https://doi.org/10.1016/j.proeng.2015.07.033

Anuntasena, W., Lenwari, A., \& Thepchatri, T. (2019). Finite Element Modelling of Concrete-Encased Steel Columns Subjected to Eccentric Loadings. Engineering Journal. https://doi.org/10.4186/ej.2019.23.6.299

Atteya, M., Shaat, A., \& Sayed-Ahmed, E. Y. (2017). Effect of CFRP Bonded Length on the Strength of Axially Loaded HSS. Al-Azhar University Civil Engineering Research Magazine (CERM), 39, 2, 89-96.

Avci-Karatas, C. (2020). Time History Analysis of a Reinforced Concrete (RC) Building in Hilly Terrain Subjected to Earthquake. 6th International Congress on Engineering, Architecture and Design, Istanbul/Turkey.

Baru, A. (2017). An Investigation of Buckling Phenomenon in Steel Elements. Heriot Watt University, School of Energy, Geoscience, Infrastructure and Society. https://doi.org/10.13140/RG.2.2.36815.48803

Bedon, C., \& Amadio C. (2017). Structural glass elements: Unified approach for the buckling verification. Structural, 212. https://doi.org/10.12917/STRU212.18
Bedon, C., \& Amadio C. (2018). Buckling analysis and design proposal for 2-side supported double Insulated Glass Units (IGUs) in compression. Engineering Structures, 168, 23-34. https://doi.org/10.1016/j.engstruct.2018.04.055

Beylergil, B., Aktaş, A., \& Cunedioglu, Y. (2012). Buckling and compressive failure of stepped lap joints repaired with composite patches. Journal of Composite Materials, 26, 3213. https://doi.org/10.1177/0021998312437001

Bijlaard, P. P. (1949). Theory and tests on the plastic stability of plates and shells. Journal of the Aeronautical Sciences, 16(9), 529-541. https://doi.org/10.2514/8.11851

Bleich, F. (1952). Buckling strength of metal structures. Mc Graw-Hill Book Company, Inc., Cardnr. 51-12588. https://repository.tudelft.nl/islandora/object/uuid:b3 915fc7-3a82-48ad-956b-29fbcceb46ae

Brank, B., Perić, D., \& Damjanić, F. B. (1997). On Large Deformations of Thin Elasto-Plastic Shells: Implementation of a Finite Rotation Model for Quadrilateral Shell Element. International Journal for Numerical Methods in Engineering. 40. 689-726. https://doi.org/10.1002/(SICI)10970207(19970228)40:4<689::AID-NME85>3.0.CO;2-7

Brasil, R., \& Wahrhaftig, A. d. M. (2018). Experimental Evaluation of the Effect of Geometric Nonlinearities on Structural Resonances. Lecture Notes in Civil Engineering, 611-618. https://doi.org/10.1007/9783-319-67443-8_53

Březina, V. (1966). Stateczność prętów konstrukcji metalowych. Arkady. Warszawa. https://archiwum.allegro.pl/oferta/statecznoscpretow-konstrukcji-metalowych-spisi6211673367.html

Broszko, M. (1953). Über die unelastische Knickung prismatischer Stäbe.

Can, Y., Güçlü, H., Kasar, İ., \& Yazici, M. (2018). Finite Element Simulation of The Telescopic Crash Boxes Designing by Adhesively Bonded Coaxial Aluminum Tubes. In 5th International Conference on Computational and Experimental Science and Engineering (ICCESEN-2018), 12-16 October, Antalya-Turkey.

D’Aniello, M., Della Corte, G., \& Mazzolani, F. M. (2006, August). Seismic upgrading of RC buildings by buckling restrained braces: experimental results vs. numerical modeling. In Proceedings of Fifth International Conference on Behavior of Steel Structures in Seismic Areas (STESSA 2006).

Doan, Q. H., Thai, D.-K., \& Tran, N. L. (2020). A Numerical Study of the Effect of Component Dimensions on the Critical Buckling Load of a GFRP Composite Strut under Uniaxial Compression. Materials, 13, 931. https://doi.org/10.3390/ma13040931 
Dubina, D., \& Ungureanu, V. (2000). Elastic-plastic interactive buckling of thin-walled steel compression members. https://scholarsmine.mst.edu/isccss/15iccfss/15iccfss -session4/2/

Eissa, M, Saeed, N. A, \& El-Ganini, W.A. (2014). Saturation-based active controller for vibration suppression of a four-degree-of-freedom rotorAMB system. Nonlinear Dynamics 76(1), 743-764. https://doi.org/10.1007/s11071-013-1166-3

Engesser, F. (1889). Ober Die Knickfestigkeit Gerader Stabe (On the Buckling Strength of Straight Struts) Zeitschrift fur Architektur und Ingenieurwesen.

Euler, L. (1744). Methodus inveniendi lineas curvas maximi minimive proprietate gaudentes. Apud Marcum-Michaelem Bousquet.

Fraldi, M., Nunziante, L., Carannante, F., Prota, A., Manfredi, G., \& Cosenza, E. (2008). On the prediction of the collapse load of circular concrete columns confined by FRP. Engineering Structures, $30(11)$, 3247-3264 https://doi.org/10.1016/j.engstruct.2008.04.036

Gerard, G. (1957). Plastic stability theory of thin shells. J. Aeron. Sci. 24 (4), 269-274. https://doi.org/10.2514/8.3828

Gerard, G. (1962). Plastic stability theory of geometrically orthotropic plates and cylindrical shells. Journal of the Aerospace Sciences, 29(8), 956-962. https://doi.org/10.2514/8.9666

Gerard, G., \& Becker, H. (1957). Handbook of structural stability: part I, buckling of flat plates, NACA Tech (No. 3781). Note.

Goroshko, A., Royzman, V., \& Petraschuk, S. (2020). Simulation of a thin long rod that does not have critical forces and does not lose stability to Euler. Problems of Tribology, 25, 3/97-2020, 25-3 I. https://doi.org/10.31891/2079-1372-2020-97-3-25-31

Isleem, H., Wang, Z., Wang, D., \& Smith, S. (2018). Monotonic and Cyclic Axial Compressive Behavior of CFRP-Confined Rectangular RC Columns. Journal of Composites for Construction, 22. https://doi.org/10.1061/(ASCE)CC.19435614.0000860

Ismail, M. R. (2011). Evaluating the Dynamical Behavior and Stability of Pipes Conveying Fluid (Doctoral dissertation, Ph. D. Thesis AL-Nahrain University, mechanical engineering).

Ivanov, A. I. (2019). Vibrations of Shaft Caused by Inertial Excitations. Journal of Mining and Geological Science, 62, 19-24.

Jakab, A., Nehme, K., \& Nehme, S. G. (2016, April). Fracture behaviour of glass columns experimental study of axial loaded glass columns. In IOP Conference Series: Materials Science and Engineering (Vol. 123, No. 1, p. 012056). IOP Publishing. $\quad$ https://doi.org/10.1088/1757899X/123/1/012056
Jasiński, F. (1894). On Longitudinal Bending Strength (in Russian), St. Petersburg. https://pl.wikipedia.org/wiki/Feliks_Jasi\%C5\%84ski \#cite_note-6

Jasiński, F. (1895). Badania nad sztywnością prętów ściskanych (in Polish). Przegląd Techniczny, Warszawa.

Johnson, C. G., Jain, U., Hazel, A. L., Pihler-Puzović, D., \& Mullin, T. (2017). On the buckling of an elastic holey column. Proceedings of the Royal Society A: Mathematical, Physical and Engineering Sciences, $\quad 473(2207), \quad 20170477$. https://doi.org/10.1098/rspa.2017.0477

Kalamara, R., Bedon, C., \& Eliášová, M. (2016). Experimental investigation for the structural performance assessment of square hollow glass columns. Engineering Structures 113(4), 1-15. https://doi.org/10.1016/j.engstruct.2016.01.028

Kambe, W., Takahashi, S., Ito, T., \& Aoki, K. (2013). An experimental study on compression resistant performance of thick plywood as an axial member. Journal of Structural and Construction Engineering (Transactions of AIJ). 78. 355-361. https://doi.org/10.3130/aijs.78.355

Kármán, T. (1908). Die knickfestigkeit gerader stäbe. Physikalische zeitschrift, 9(4), 136-140.

Kármán, T. (1910). Untersuchungen über Knickfestighkeit. Mitteilungen über Forschungsarbeiten auf dem Gebiete des Ingenieurwesens, 81, Berlin. https://link.springer.com/chapter/10.1007\%2F978-3662-01994-8_1

Kiss, L. (2020a). Stability of fixed-fixed shallow arches under arbitrary radial and vertical forces. Magazine of Civil Engineering, 95, 31-41. https://doi.org/10.18720/MCE.95.3

Kiss, L. (2020b). Stability of pinned-rotationally restrained arches. Theoretical and Applied Mechanics, 10-10. https://doi.org/10.2298/TAM200402010K

Krishan, A. L., Chernysova, E. P., \& Astafyeva, M. A. (2019, December). Behavior of compressed concrete in a glass fiber-reinforced shell. In IOP Conference Series: Materials Science and Engineering (Vol. 687, No. 3, p. 033034). IOP Publishing.

Kudryavtsev, S. (2019). Buckling behavior of steel column with triangularly corrugated web. MATEC Web of Conferences, 279 (23-26), 02007. https://doi.org/10.1051/matecconf/201927902007

Kukhar, V., Artiukh, V., Serduik, O., \& Balalayeva, E. (2016). Form of Gradient Curve of Temperature Distribution of Lengthwise the Billet at Differentiated Heating before Profiling by Buckling. Procedia Engineering, 165, 1693-1704. https://doi.org/10.1016/j.proeng.2016.11.911 
Lepik, Ü. (1999). Bifurcation analysis of elastic-plastic cylindrical shells. International journal of non-linear mechanics, 34(2), 299-311. https://doi.org/10.1016/S0020-7462(98)00032-8

Li, Z., He, M., Tao, D., \& Li, M. (2015). Experimental buckling performance of scrimber composite columns under axial compression. Composites Part B Engineering 86. https://doi.org/10.1016/j.compositesb.2015.10.023

Lilkova-Markova, S., \& Dzhupanov, V. (2001). Dynamic Stability of Cantilevered Pipes Supported by Additional Structural Spring Supports. Part 1, Short Pipes. National Congress of TAM, 528-534.

Lilkova-Markova, S., \& Lolov, D. (2018). Multi-Segment Integration Technique for Solving the Stability Problem of an Axially Compressed Column. In XVIII Anniversary International Scientific Conference by Construction and Arhitecture VSU'2018.

Lolov, D., \& Lilkova-Markova, S. (2006). Dynamic stability of a curved pipe bent in the arc of a circle on hinge supports at the ends. Sadhana, 31, 537-541. https://doi.org/10.1007/BF02715912

Łukowicz, A., Deniziak, P., Migda, W., GordziejZagórowska, M., \& Szczepański, M. (2016). Innovative cold formed GEB section under compression. In Proceedings of the XIII International Conference on Metal Structures-ICMS 2016 Zielona Góra, Recent Progress in Steel and Composite Structures (pp. 76-77). Balkema: CRC Press. https://doi.org/10.1201/b21417-14

Massumi, A., Sadeghi, K., \& Moshtagh, E. (2018). Effects of Deviation in Materials' Strengths on the Lateral Strength and Damage of RC Frames. Structural Engineering \& Mechanics, 68, 289-297. https://doi.org/10.12989/sem.2018.68.3.289

Megahed, K. (2016). Experimental and Theoretical Analysis of Concrete Encased Cold Formed Steel Composite Column. Thesis for Master Degree. https://doi.org/10.13140/RG.2.2.20548.48005

Mehrabi, P., Honarbari, S., Rafiei, S., Jahandari, S., \& Bidgoli, M. A. (2021). Seismic response prediction of FRC rectangular columns using intelligent fuzzy-based hybrid metaheuristic techniques. Journal of Ambient Intelligence and Humanized Computing, 1-19. https://doi.org/10.1007/s12652-020-02776-4

Milašinović, D. D., Vlajić, L. M., \& Miličić, I. M. (2003). Prediction of buckling curves of steel columns using by rheological analogy. Materials and Structures, 3-13. http://scindeks.ceon.rs/article.aspx?artid=0543$07980304008 \mathrm{M}$

Murawski, K. (1992). Stability of thin shell columns in elasto-plastic states. 14 Międzynarodowe Sympozjum Naukowe Studentów i Młodych Pracowników Nauki. Mechanika, Zielona Góra, 38-43.
Murawski, K. (1999). The Modelling of Energy Consuming Process in Layered Vehicles Bumper (Doctoral dissertation, Doctor's thesis. Poznan University of Technology, Faculty of Hardworking Machines and Vehicles). https://www.researchgate.net/publication/324557 765_Modelowanie_procesu_pochlaniania_energii _w_warstwowych_zderzakach

Murawski, K. (2002a). The Engesser-Shanley modified theory of stability of thin-walled cylindrical rods with example of use for steel St35. Acta Scientiarum Polonorum ArchitecturaBudownictwo, 1-2.

Murawski, K. (2002b). Stability analysis of a thinwalled plywood cylindrically shaped element. Annals of Warsaw Agricultural University, Forestry and Wood Technology, Special Number I, Warsaw Agricultural University Press, Warsaw, 230-234.

Murawski, K. (2003). Theory of stability of layered cylindrical rods in elasto-plastic states exemplified by steel R35. Electronic Journal of Polish Agricultural Universities. Civil Engineering, 6(2). http://www.ejpau.media.pl/articles/volume6/issue2/c ivil/art-02.pdf

Murawski, K. (2007a). Movement of the neutral layer during lose of stability in the critical cross section of very slender cylindrical shaped plywood compressed by ball-and socket joints, Annals of Warsaw University of Life Sciences - SGGW Forestry and Wood Technology, 62, 67-69.

Murawski, K. (2008a). Critical stress of squat cylindrical and square shaped plywood compressed by ball-andsocket joints according to the Tetmajer-Jasiński hypothesis. Annals of Warsaw University of Life Sciences - SGGW Forestry and Wood Technology No 64, 2008: 113-115.

Murawski, K. (2008b). Critical stress of squat cylindrical and square shaped plywood compressed by ball-andsocket joints according to the Johnson-Ostenfeld hypothesis, Krzysztof Murawski, Annals of Warsaw University of Life Sciences - SGGW Forestry and Wood Technology No 64, 2008: 127-129.

Murawski, K. (2008c). Critical stress of squat cylindrical and square shaped plywood made of birch compressed by ball-and-socket joints according to the Ylinen hypothesis Annals of Warsaw University of Life Sciences - SGGW Forestry and Wood Technology, 64, 120-123

Murawski, K. (2008d). Critical stress of squat cylindrical and square shaped plywood made of birch compressed by ball-and-socket joints according to the Březina's hypothesis, Annals of Warsaw University of Life Sciences - SGGW Forestry and Wood Technology, 64, 124-126. 
Murawski, K. (2008e). Critical stress of squat cylindrical and square shaped plywood made of birch compressed by ball-and-socket joints according to the Engesser-Kármán-Shanley's modified hypothesis, Annals of Warsaw University of Life Sciences SGGW Forestry and Wood Technology, 64, 116-119

Murawski, K. (2011a). Teoria technicznej stateczności smukłych prętów sklejkowych. Oficyna Wydawnicza Politechniki Warszawskiej. ISBN 978-83-7207-959-6

Murawski, K. (2011b). Theory of Technical Stability of Slender Plywood Rods. Publishing House of Warsaw University of Technology. ISBN 978-83-7207-968-8

Murawski, K. (2011c). Modelowanie procesu pochłaniania energii w warstwowych zderzakach. Oficyna Wydawnicza Politechniki Warszawskiej. ISBN: 978-83-7207-973-2

Murawski, K. (2017a). Modelling of the Energyabsorptive Process in Layered Bumpers. ISBN 9781-387-37333-8.

Murawski, K. (2018). Technical Stability of Very Slender Thin-walled Orthotropic Columns. ISBN 978-0-359-01937-3.

Murawski, K. (2020a). Lateral Buckling in Elasticplastic States of Thin-walled Semi-slender Columns Made of Steel R35 According to Known Hypotheses. DOI: 10.13140/RG.2.2.23578.59845

Murawski, K. (2020b). Experimental Results of Lateral Buckling of Thin-walled Semi-slender Columns with Pinned Ends Made of Steel R35 in the Elasticplastic States in Comparison to the Known Hypotheses. DOI: 10.13140/RG.2.2.21559.75688

Murawski, K. (2020c). Comparison of the Known Hypotheses of Lateral Buckling in the ElasticPlastic States of Thin-Walled Semi-Slender Columns. International Journal of Structural Glass and Advanced Materials Research, 4(1), 233-253. https://doi.org/10.3844/sgamrsp.2020.233.253

Murawski, K., \& Kłos, R. (2007). Experimental determining of extensions during test of stability of the rode $870 \times 412 \mathrm{~mm}$ made of pine compressed by ball-and-socket joints. Annals of Warsaw University of Life Sciences-SGGW Forestry and Wood Technology, (62), 70-72.

Nakashima, M., Iwai, S., Iwata, M., Takeuchi, T., Konomi, S., Akazawa, T., \& Saburi, K. (1994). Energy dissipation behavior of shear panels made of low yield steel. Earthquake Engineering \& Structural Dynamics, 23, 1299-1313. https://doi.org/10.1002/eqe.4290231203

Naseri, R., Showkati, H., \& Firouzsalari, S. E. (2020). Buckling behaviour of GFRP cylindrical shells subjected to axial compression load. Composite Structures. https://doi.org/10.1016/j.compstruct.2020.113269
Nazarimofrad, E., \& Shokrgozar, A. (2019). Seismic performance of steel braced frames with selfcentering buckling-restrained brace utilizing superelastic shape memory alloys. The Structural Design of Tall and Special Buildings, 28. https://doi.org/10.1002/tal.1666

Oliveira, T. V., Dias, C. A. C., Sousa, R. A., Pasquetti, E., \& Souza, R. M. D. (2017). Analytical study of the shear effect on the buckling of columns on elastic medium. https://doi.org/10.20906/CPS/CILAMCE2017-0274

Ostenfeld, A. (1898). Exzentrische und zentrische Knickfestigkeit. VDI-Z, 94, 1462-1470.

Özbaşaran, H., Aydın, R., \& Dogan, M. (2015). An alternative design procedure for lateral-torsional buckling of cantilever I-beams. Thin-Walled Structures, 90, 235-242. https://doi.org/10.1016/j.tws.2015.01.021

Papanastasiou, P., \& Durban, D. (1999). Bifurcation of elastoplastic pressure-sensitive hollow cylinders. https://doi.org/10.1115/1.2789138

Patel, V., Liang, Q., \& Hadi, M. (2015). Nonlinear Analysis of Concrete-Filled Steel Tubular Columns. Scholar's Press. ISBN: 978-3-639-66536-9

Pearson, C. E. (1950). Bifurcation criterion and plastic buckling of plates and columns. Journal of the Aeronautical Sciences, 17(7), 417-424. https://doi.org/10.2514/8.1674

Phungpaingam, B., Athisakul, C., \& Chucheepsakul, S. (2011). Alternative Model for Postbuckling Analysis of a Nonlinearly Elastic Column. 16th National Convention in Civil Engineering. Chonburi, Thailand, Volume: STR0038.

Pinarbasi, S., Genc, T., Akpinar, E., \& Okay, F. (2020). Comparison of Design Guidelines for Hot-Rolled IShaped Steel Compression Members according to AISC 360-16 and EC3. Advances in Civil Engineering, 1-20. https://doi.org/10.1155/2020/6853176

Qays, S., \& Al-Zuhairi, A. (2020). Structural Performance of Slender RC Columns with Cross and Square-Shaped under Compression Load. IOP Conference Series: Materials Science and Engineering, 881, 012040. https://doi.org/10.1088/1757-899X/881/1/012040

Qi, Y., Xie, L., Bai, Y., Liu, W., \& Fang, H. (2019). Axial Compression Behaviours of Pultruded GFRP-Wood Composite Columns. Sensors, 19(4), 755. https://doi.org/10.3390/s19040755

Radhakrishnan, S. (1956). Plastic buckling of circular cylinders. Journal of the Aeronautical Sciences, 23(9), 892-894.

Rajkannu, S., \& Sanjeevi, A. J. (2020). Flexural-torsional buckling strength of thin-walled channel sections with warping restraint. Journal of Constructional Steel Research, 169, 106041. https://doi.org/10.1016/j.jcsr.2020.106041 
Razdolsky, A. G. (2018). Determination of Slenderness Ratio for Laced and Battened Columns. Practice Periodical on Structural Design and Construction, 23(4). https://doi.org/10.1061/(ASCE)SC.19435576.0000383

Roy, K., Ting, T. C. H., Lau, H. H., \& Lim, J. B. P. (2019). Experimental and numerical investigations on the axial capacity of cold- formed steel built-up box sections. Journal of Constructional Steel Research. https://doi.org/10.1016/j.jcsr.2019.05.0388

Saberi, H., Kolmizadeh, V., Mokhtari, A., \& Saberi, V. (2020). Investigating of the Effect of Concrete Confinement on the Axial Performance of Circular Concrete Filled Double-Skin Steel Tubular (CFDST) Long

Columns. https://doi.org/10.22075/JRCE.2020.19167.1362

Saeed, N. A. (2019). On vibration behavior and motion bifurcation of a nonlinear asymmetric rotating shaft. Arch Applied Mech 89, 1899-1921. https://doi.org/10.1007/s00419-019-01551-y

Saeed, N. A. (2020). On the steady-state forward and backward whirling motion of asymmetric nonlinear rotor system. European Journal of MechanicsA/Solids $80, \quad 103878$. https://doi.org/10.1016/j.euromechsol.2019.103878

Saeed, N. A., \& Eissa, M. (2018). Bifurcations of periodic motion of a horizontally supported nonlinear Jeffcott-rotor system having transversely cracked shaft. International Journal of Non-Linear Mechanics, 101, 113-130. https://doi.org/10.1016/j.ijnonlinmec.2018.02.005

Saeed, N. A., \& Eissa, M. (2019). Bifurcation Analysis of a Transversely Cracked Nonlinear Jeffcott-rotor System at Different Resonance Cases. International Journal of Acoustics and Vibration, 24(2), 284-302. https://doi.org/10.20855/ijav.2019.24.21309

Saeed, N. A, Mahrous, E., \& Awrejcewicz, J. (2020a). Nonlinear dynamics of the six-pole rotor-AMB system under two different control configurations. Nonlinear Dynamics, 101 (4), 2299-2323. https://doi.org/10.1007/s11071-020-05911-0

Saeed, N. A., Awwad, E. M., El-Meligy, M. A., \& Abouel-Nasr, E. (2020b). Radial versus Cartesian control strategies to stabilize the nonlinear whirling motion of the six-pole rotor-AMBs. IEEE Access, 8, $138859-138883$. https://doi.org/10.1109/ACCESS.2020.3012447

Saeed, N.A., Mohamed, M.S., \& Elagan, S. K. (2020c). Periodic, Quasi-Periodic and Chaotic Motions to Diagnose a Crack on a Horizontally Supported Nonlinear Rotor System. Symmetry, 12(12), 2059. https://doi.org/10.3390/sym12122059

Saeed, N. A., Awwad, E. M., El-Meligy, M. A., \& Abouel-Nasr, E. (2021a) Analysis of the rub-impact forces between a controlled nonlinear rotating shaft system and the electromagnet pole legs. Applied Mathematical Modelling. (Accepted). https://doi.org/10.1016/j.apm.2021.01.008
Saeed, N. A., Awwad, E. M., El-Meligy, M. A., \& AbouelNasr, E. (2021b).Sensitivity analysis and vibration control of asymmetric nonlinear rotating shaft system utilizing 4-pole AMBs as an actuator. European Journal of Mechanics - A/Solids, 86, 104145 https://doi.org/10.1016/j.euromechsol.2020.104145

Saingam, P., Sutcu, F., Terazawa, Y., Fujishita, K., Lin, P.-C., Celik, O., \& Takeuchi, T. (2020). Composite behavior in RC buildings retrofitted using bucklingrestrained braces with elastic steel frames. Engineering Structures, 219, 110896 https://doi.org/10.1016/j.engstruct.2020.110896

Sanchez, H., \& Salas, C. C. (2008). Deformation of Steel Straight Pipes with Internal Pressure Under Axial Compression and Bending Load by Seismic Action. Proceedings of the International Conference on Offshore Mechanics and Arctic Engineering - OMAE, 3. https://doi.org/10.1115/OMAE2008-57491

Seide, P., Weingarten, V. I., \& Morgan, E. J. (1960). The development of design criteria for elastic stability of thin shell structures (No. EM-10-26). TRW Space Technology Labs Los Angeles CA. https://doi.org/10.21236/AD0490800

Seyranian, A. P., \& Privalova, O. G. (2003). The Lagrange problem on an optimal column: Old and new results. Structural and Multidisciplinary Optimization, 25(5), 393-410. https://doi.org/10.1007/s00158-003-0333-4

Shanley, F. R. (1947). Inelastic column theory. Journal of the aeronautical sciences, 14(5), 261-268. https://doi.org/10.2514/8.1346

Silvestre, N., Abambres, M., \& Camotim, D. (2018). Influence of the deformation mode nature on the $1 \mathrm{st}$ order post-yielding strength of thin-walled beams. Thin-Walled Structures, 128, 71-79. https://doi.org/10.1016/j.tws.2017.09.027

Simão, P. D., Rodrigues, J. P., Barros, H., Ferreira, C., Adam, J. M., \& Delatte, N. (2019). GBT RayleighRitz analysis of slender elasto-plastic steel columns under fire conditions. In Proceedings of the 3rd International Conference on Recent Advances in Nonlinear Design Resilience and Rehabilitation of StructuresCOIMBRA (pp. 436-447).

Slimani, A., Ammari, F., \& Adman, R. (2018). The effective length factor of columns in unsymmetrical frames asymmetrically loaded. Asian Journal of Civil Engineering, 19(4). https://doi.org/10.1007/s42107-018-0038-z

Słowiński, K., \& Piekarczyk, M. (2017). Determination of the plastic limit load for a cylindrical shell under general loading conditions using FEA. Ce/Papers, 1(2-3), 980-989. https://doi.org/10.1002/cepa.138

Stowell, E. Z. (1948). A Unified theory of plastic buckling of columns and plates, NACA Tech. Note. 
Tarsha, I., \& Takla, M. (2016). Ultimate load for composite column subjected to ISO 834 fire. https://www.researchgate.net/publication/33247073 1_Ultimate_load_for_composite_column_subjected _to_ISO_834_fire

Terazawa, Y., Suma, K., Iwanaga, M., Maehara, S., \& Takeuchi, T. (2020). Buckling Strength of Latticed Domes of Grid-Purlin with Beams. AIJ Journal of Technology and Design, 26, 899-904. https://doi.org/10.3130/aijt.26.899

Tetmajer, L. (1886). Mittheilungen der Anstalt zur Prüfung von Baumaterialien am eidg. Polytechnikum in Zürich. 1.Heft: Methoden und Resultate der Prüfung natürlicher und künstlicher Bausteine, Zürich.

Thumrongvut, J., \& Tiwjantuk, P. (2018). Strength and Axial Behavior of Cellular Lightweight ConcreteFilled Steel Rectangular Tube Columns under Axial Compression. Materials Science Forum. 941. 2417-2422. https://doi.org/10.4028/www.scientific.net/MSF.941 .2417

Viana, H., Lanna, R., Costa, R., \& Lavall, A. (2020). Formulation for nonlinear dynamic analysis of steel frames considering the plastic zone method. Engineering Structures, 223 https://doi.org/10.1016/j.engstruct.2020.111197

Virgens, J., Gomes, R., Trautwein, L., Guimarães, G., \& Vaz, A. (2019). Experimental analysis of eccentrically loaded reinforced concrete columns with an added jacket of self-compacting concrete. Revista IBRACON de Estruturas e Materiais, 12, 329-336. https://doi.org/10.1590/s198341952019000200007

Vol'mir, A. S. (1965). Stability of elastic systems. Foreign technology Division, Wright Patterson Air Force Base,

Ohio. https://apps.dtic.mil/sti/citations/AD0628508

Voyiadjis, G. Z., \& Woelke, P. (2008). Elasto-plastic and damage analysis of plates and shells. Springer Science \& Business Media. ISBN-10: 3540793518.

Wahrhaftig, A. d. M. (2020). Time-dependent analysis of slender, tapered reinforced concrete columns. Steel and Composite Structures, 36(2), 229-247. http://dx.doi.org/10.12989/scs.2020.36.2.229

Wahrhaftig, A. d. M., Brasi, R. M. L. R. F., \& Machado, M.A.S. (2008). Evaluation of the Buckling Critical Load of Bars Subjected to their Self-Weight. The Ninth International Conference on Computational Structures Technology. https://doi.org/10.4203/ccp.88.13

Wahrhaftig, A. d. M., Brasil, R. M. L. R. F., \& César, S. F. (2016). Creep in the fundamental frequency and stability of a slender wooden column of composite section. https://doi.org/10.1590/0100-
Wahrhaftig, A. d. M., Magalhães, K. M. M., \& Nascimento, L. S. M. S. C. (2021). Stress assessment in reinforcement for columns with concrete creep and shrinkage through Brazilian technical normative. J Braz. Soc. Mech. Sci. Eng. 43, 6. https://doi.org/10.1007/s40430-020-02731-6

Wahrhaftig, A. d. M., Silva, M. A., \& Brasil, R. M. L. R. F. (2019). Analytical determination of the vibration frequencies and buckling loads of slender reinforced concrete towers. Latin American Journal of Solids and Structures, 16. https://doi.org/10.1590/1679-78255374

Wahrhaftig, A. d. M., Magalhaes, K., \& Siqueira, G. H. (2020a). Evaluation of limit state of stress and strain of free-fixed columns with variable geometry according to criteria from the Brazilian code for concrete structures. Latin American Journal of Solids and Structures, 17. https://doi.org/10.1590/1679-78255780

Wahrhaftig, A. M., Magalhaes, K., Brasil, R. M. L. R. F., \& Murawski K. (2020b). Evaluation of Mathematical Solutions for the Determination of Buckling of Columns Under Self-weight. https://doi.org/10.1007/s42417-020-00258-7

Yiotis, A., Katsikadelis, J. T., \& Kounadis, A. (1982). Stability Analysis of Box-Shaped Structures of Rectangular Cross-Section. Revue Roumaine des Sciences Techniques. Serie Mecanique Appliquee, 27, 681-695. https://pascalfrancis.inist.fr/vibad/index.php?action=getRecordDe tail\&idt=PASCALBTP83X0241807

Ylinen, A. (1956). A method of determining the buckling stress and the required cross-sectional area for centrally loaded straight columns in elastic and inelastic range. Mem Assoc Int Ponts Charpentes, 16, 529-550. https://ci.nii.ac.jp/naid/10006136314/

Zhou, L., Tang, J., Wang, W., Zhao, E., Ren, S., Zhang, Q., \& Liu, P. (2019). An accurate method for the calculation of ultimate load in lattice boom. Advances in Mechanical Engineering, 11, 168781401988677. https://doi.org/10.1177/1687814019886774

Zucco, G., Oliveri, V., Rouhi, M., Telford, R., Clancy, G., McHale, C., ... \& Peeters, D. (2020). Static test of a variable stiffness thermoplastic composite wingbox under shear, bending and torsion. The Aeronautical Journal, 124(1275), 635-666. https://doi.org/10.1017/aer.2019.161 